\title{
COVID-19 Vaccination Mandates and Vaccine Uptake
}

\author{
Alexander Karaivanov ${ }^{\S *}$, Dongwoo Kim ${ }^{\S}$, Shih En Lu ${ }^{\S}$, Hitoshi Shigeoka ${ }^{\S \dagger *}$ \\ ${ }^{\S}$ Department of Economics, Simon Fraser University \\ ${ }^{\dagger}$ Graduate School of Public Policy, University of Tokyo, IZA, and NBER
}

January 12, 2022

\begin{abstract}
We evaluate the impact of government-mandated proof of vaccination requirements for access to public venues and non-essential businesses on COVID-19 vaccine uptake. We find that the announcement of a mandate is associated with a rapid and significant surge in new vaccinations (more than $60 \%$ increase in weekly first doses), using the variation in the timing of these measures across Canadian provinces in a difference-indifferences approach. Time-series analysis for each province and for France, Italy and Germany corroborates this finding. Counterfactual simulations using our estimates suggest the following cumulative gains in the vaccination rate among the eligible population (age 12 and over) as of October 31, 2021: up to 5 percentage points (p.p.) (90\% CI 3.9-5.8) for Canadian provinces, adding up to 979,000 (425,000-1,266,000) first doses in total for Canada ( 5 to 13 weeks after the provincial mandate announcements), 8 p.p. (4.3-11) for France (16 weeks post-announcement), 12 p.p. (5-15) for Italy (14 weeks post-announcement) and 4.7 p.p. (4.1-5.1) for Germany (11 weeks post-announcement).
\end{abstract}

Keywords: COVID-19, vaccine mandates, proof of vaccination, vaccine uptake, vaccine hesitancy, difference-in-differences, time-series analysis, counterfactuals

JEL codes: I18, I12, C23

${ }^{*}$ Corresponding authors: H. Shigeoka, hitoshi_shigeoka@sfu.ca; A. Karaivanov, akaraiva@sfu.ca. 
medRxiv preprint doi: https://doi.org/10.1101/2021.10.21.21265355; this version posted January 13, 2022. The copyright holder for this preprint (which was not certified by peer review) is the author/funder, who has granted medRxiv a license to display the preprint in perpetuity. All rights reserved. No reuse allowed without permission.

\section{Introduction}

Immunization with mRNA or adenoviral vaccines has proven very effective for reducing the spread and severity of COVID-19, with vaccinated people benefiting from a large reduction in the risk of severe outcomes. ${ }^{1}$ Yet, following a quick-paced uptake in early 2021, COVID-19 immunization rates in many countries slowed down significantly, at about $60 \%$ of the population, during the summer despite the vaccines' proven benefits (see Fig. B1). In addition, most countries or regions, even those with high vaccination rates, experienced increased viral transmission or had to maintain or re-introduce non-pharmaceutical interventions such as mask-wearing mandates or indoor capacity limits in fall 2021 because of the elevated reproduction rate of the Delta variant. ${ }^{2}$

A further increase in vaccination rates therefore remains essential for reducing the health and economic impacts of COVID-19 and allowing the eventual lifting of restrictions. Moreover, the administration of booster doses or vaccines with updated formulations may be necessary in the face of new variants. Public health authorities all over the world have actively sought the most effective strategies to increase vaccine uptake and provide incentives for hesitant, procrastinating or other people who have had the opportunity to be immunized for a prolonged time but have not taken it up.

In response to this challenge, many local or national governments have recently introduced proof of vaccination mandates, which allow only vaccinated persons to attend non-essential sports or social activities, events and settings such as concerts, stadiums, museums, restaurants, bars, etc. ${ }^{3}$ Some mandates accept a recent negative COVID test or past positive test as a substitute of vaccination or allow businesses to opt out if they abide by additional restrictions. ${ }^{4}$ The goal of these policies is twofold: to provide incentives for immunization and to reduce viral transmission in risky indoor or crowded settings. ${ }^{5}$

We evaluate and quantify the effect of proof of vaccination mandates on first-dose vaccine uptake in the ten Canadian provinces and three European countries (France, Italy and

\footnotetext{
${ }^{1}$ Scobie et al. (2021), Grannis et al. (2021), Andrews et al. (2021) and Gupta et al. (2021).

${ }^{2}$ For example, by early August, all four of Canada's Western provinces had removed their mask-wearing mandates for public indoor spaces. By mid-September, all re-imposed a mask mandate, either preemptively or after a COVID surge. The largest provinces Ontario and Quebec did not remove their mask mandates.

${ }^{3}$ While the mandates are sometimes colloquially called "vaccine passports", we deliberately avoid this politicized term.

${ }^{4}$ Among the jurisdictions considered in this study, the mandates in France, Italy, Germany, Alberta and Saskatchewan allowed such options during the analyzed period - see the notes to Table C5 for details.

${ }^{5}$ Several countries have also planned or implemented vaccination mandates for employees (USA for all firms with more than 100 employees, Italy for all employees, Canada for all federal employees), and a broader mandate is under consideration in Austria. We do not analyze these alternative mandates.
} 
Germany) that announced and implemented such mandates in the period July-October, 2021. This is a period without binding vaccine supply or access constraints and with a high base first-dose vaccination rate (above $60 \%$ of those eligible in the three countries and above $80 \%$ in Canada, at the time of the mandate announcements). Hence, we evaluate the mandates' impact on people, such as the vaccine hesitant, that have remained unvaccinated for weeks or months after immunization became available to them.

While requiring proof of vaccination is expected to raise vaccine uptake, the magnitude and speed of the increase are hard to predict: they depend on the relative importance of the factors leading to delay or hesitancy, e.g., lack of social or economic incentives, misinformation, or entrenched political or religious beliefs. We use first doses as the main outcome in our statistical analysis because they most directly reflect the decision to be immunized. ${ }^{6}$

The Canadian provincial data is key for our identification strategy as it allows us to use the time variation in mandate announcement dates (from August 5, 2021 in Quebec to September 21, 2021 in Prince Edward Island) across different geographic units in the same country, via a difference-in-differences (DID) approach. ${ }^{7}$ In contrast, the French, Italian or German mandates, or the announced U.S. vaccine mandate for employees, apply at the national level, which makes it more challenging to separate the effect of the mandate from that of time trends or other concurrent events or policies.

Fig. 1 plots the weekly vaccine first doses administered in the four most populous Canadian provinces and four European countries. All except Spain had introduced a province-wide or country-wide proof of vaccination mandate in the studied period. We observe a sizable boost in vaccine uptake within two weeks after the mandate announcement date (the dashed vertical line) in all four provinces and in France, Italy and Germany, often following a sharp decline in the pre-announcement weeks. In France, daily first-dose appointments data also shows a striking surge on the day after the mandate announcement (see Fig. B2). In contrast, Spain exhibits a steady decrease in weekly first doses over the displayed period.

Motivated by this evidence, we aim to answer two important policy-relevant questions. First, what is the magnitude of the increase in the pace of first dose vaccinations after a proof of vaccination mandate announcement? Second, how long do these gains persist and

\footnotetext{
${ }^{6}$ To avoid potential bias from constrained vaccine supply affecting the pre- or post-mandate pace of vaccination, we use only data after June 15, 2021, when it is safe to assume that any age-eligible person (12 or older in Canada) was able to receive a first dose of COVID-19 vaccine with minimal delay; see Table C2.

${ }^{7}$ In Canada, the provinces are separate public health jurisdictions with extensive powers over health policy while the vaccines are procured by the federal government and allocated to the provinces in proportion to their population. All COVID-19 vaccines used in Canada during the study period, namely BNT162b2 (Pfizer /BioNTech Comirnaty), mRNA-1273 (Moderna SpikeVax) and AZD1222 (Oxford-AstraZeneca Vaxzevria), were originally considered two-dose vaccines.
} 
Figure 1: Vaccination mandates and first dose uptake
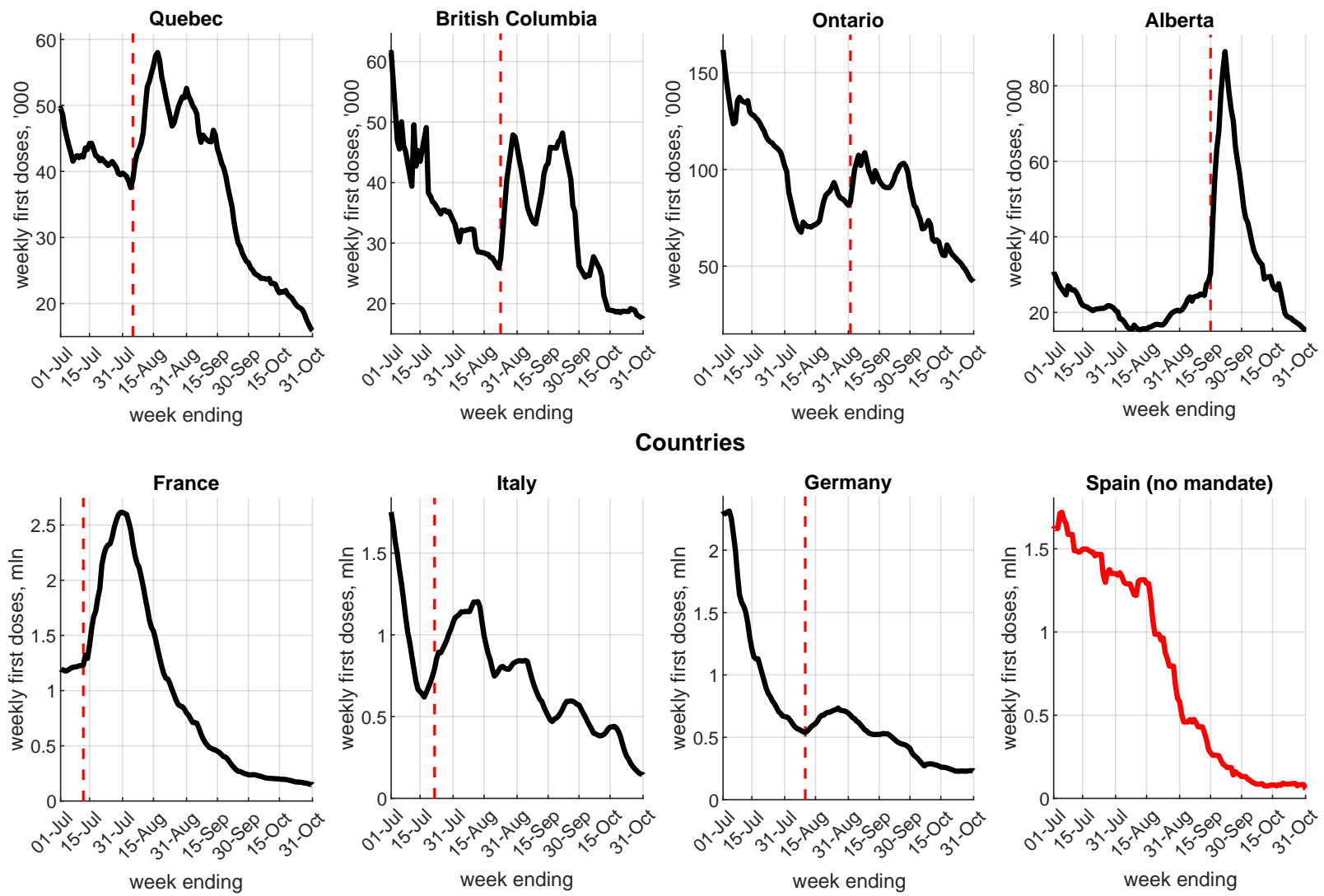

\section{Countries}
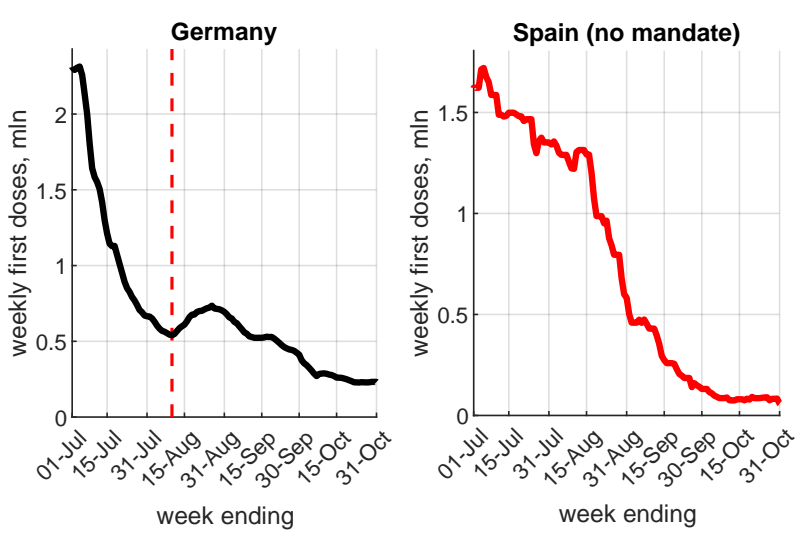

Notes: The figure plots the weekly first doses of COVID-19 vaccines administered for dates $t-6$ to $t$, where $t$ is the date on the horizontal axis. The dashed red lines denote the proof of vaccination mandate announcement dates (for countries, this is the date of a national mandate). Spain had not announced a national proof of vaccination mandate as of October 31, 2021. We show the four most populated Canadian provinces totalling about $87 \%$ of Canada's population (see Fig. B4 for all ten provinces). Alberta also had a $\$ 100$ debit card incentive for doses received between Sep. 3 and Oct. 14, 2021.

what is the cumulative effect of the mandates on vaccine uptake?

Using Canadian province-level data in a difference-in-differences (DID) statistical analysis, we find a quick and significant increase in vaccine uptake, measured by new weekly first doses, following the announcement of a proof of vaccination mandate. In our baseline DID specification, using the period June 15 to Sep. 14, 2021 and splitting the data into five 'treated' provinces (those with the earliest announcements) and five 'control' provinces (not yet announced), we estimate a $66 \%(50.6 \log \text { points, } 95 \% \text { CI } 24.5-76.7)^{8}$ average increase in weekly first doses following the mandate announcement, relative to in absence of mandate.

\footnotetext{
${ }^{8}$ Throughout the paper, we report $95 \%$ confidence intervals for parameter estimates and $90 \%$ confidence intervals for counterfactual simulation results.
} 
medRxiv preprint doi: https://doi.org/10.1101/2021.10.21.21265355; this version posted January 13, 2022. The copyright holder for this preprint (which was not certified by peer review) is the author/funder, who has granted medRxiv a license to display the preprint in perpetuity.

All rights reserved. No reuse allowed without permission.

The increased uptake is sustained over the post-announcement period with available data. We obtain similar results, more than $60 \%$ increase in weekly first doses on average over the post-announcement weeks, also when using alternative dates and treatment groups varying from the first three to the first nine provinces to announce a mandate.

We complement and extend the DID panel-data results with structural-break and timeseries analysis, which allows us to study the mandates' longer-term impact on vaccine uptake using our full dataset up to October 31, 2021 and to obtain individual policy effect estimates for each province and country. We test for the presence of a structural break at the announcement date and find that we can reject the null hypothesis of no break for each of the ten provinces and three countries. The time-series results confirm the rapid and large increase in first-dose uptake after a mandate announcement relative to the no-mandate trend found in the DID analysis. The estimated effect varies across the provinces, e.g., a 34\% (29 log points, 8.2-50.5) initial increase in Ontario vs. 326\% (145 log points, 110-181) in Alberta. We note that several factors may contribute to the heterogeneity of the estimates, including the time between the mandate announcement and implementation and the fraction of the population that is already vaccinated at the time of announcement (both are negatively correlated with the size of the estimated initial effect). We find similar results for the countries - an average estimated initial increase in weekly first doses of $17 \%$ (15.4 log points, 5.0-25.8) for France, 179\% (103 log points, 53-152) for Italy and 55\% for Germany (43.8 log points, 31.4-56.1), relative to the respective pre-mandate trends. ${ }^{9}$

Using our time-series estimates for each province in counterfactual simulations, we find large cumulative increases in the first-dose vaccination rate for all provinces, relative to in the absence of mandate: from 1.9 p.p. (90\% CI: -0.3-3.0) in Ontario to 5 p.p. (4.0-5.6) in Saskatchewan and 5 p.p. (3.9-5.8) in New Brunswick, with all other provinces in between, as of October 31, 2021. These estimated total gains in uptake add up to 2.9 p.p. (1.3-3.8) of the eligible population, or 979,000 new first doses (425,000-1,266,000), for Canada as a whole. This is a significant increase in vaccine uptake considering the relatively short time in which it was achieved and the very high pre-mandate first dose vaccination rate in Canada (over $80 \%$ on average at the time of the mandate announcements). We also estimate large increases in first-dose vaccinations relative to the no-mandate counterfactual in the three countries: 8 p.p. (4.3-10.8) or $4.59 \mathrm{mln}$ (2.47-6.25) doses in France, 12 p.p. (5.0-15.1) or $6.48 \mathrm{mln}$ (2.678.14) additional first doses in Italy, and 4.7 p.p. (4.1-5.1) or $3.47 \mathrm{mln}$ (3.06-3.81) doses in Germany as of October 31, 2021, in our baseline specification. These estimated gains are

\footnotetext{
${ }^{9}$ A comparison of Fig. 1 and Fig. B2 suggests that the relatively low French estimate for the initial policy effect may reflect a lag between appointment booking and vaccine administration.
} 
larger than that for Canada, possibly because of the earlier mandates in these countries or the lower starting vaccination rates, and they may partly reflect expanding the scope of the initial mandates, e.g., in Italy.

Vaccination mandates have been controversial, as some people perceive them as restrictions on personal freedom. This can affect compliance and increase both the direct implementation and enforcement costs, as well as the political costs of introducing a mandate. We do not address ethical considerations in this paper. Our goal is to assess the mandates' effectiveness purely in terms of raising vaccine uptake, which can then be weighed against various costs and compared to other policies including financial incentives (cash, gift cards, lotteries) or behavioral nudges (e.g., messages from experts, appointment reminders).

In related work, Mills and Rüttenauer (2021) use a synthetic control approach to evaluate the impact of COVID-19 certification mandates on vaccine uptake, overall and by age group, in six countries. The authors find significant increases in daily total vaccinations in France, Israel and Italy between 20 days prior to 40 days after the mandate implementation. ${ }^{10}$ While the main takeaway is similar, our paper differs in several important ways. First, we provide robust difference-in-differences evidence using the variation in mandate timing within the same country, Canada, in addition to evidence using time-series methods for France, Italy and Germany. Second, instead of total vaccinations, we focus on first doses, as most directly reflecting the decision to become immunized and avoiding potential issues related to second dose scheduling or availability in spring/summer 2021. This is one possible reason why, unlike Mills and Rüttenauer, we find a statistically significant increase in vaccine uptake in Germany around the mandate. ${ }^{11}$ Third, instead of using a fixed 20-day cutoff before implementation, we use the actual mandate announcement date ${ }^{12}$ as the intervention indicator and show a strong impact on vaccine uptake thereafter.

There is little evidence that financial or behavioural nudges increase the vaccination rate among hesitant people. Chang et al. (2021) report results from a mid-2021 randomized controlled trial (RCT) with unvaccinated members of a large Medicare health plan in a California county with $77 \%$ vaccination rate at the time of the study. The authors examine the effect of $\$ 10$ or $\$ 50$ financial incentives, different public health messages and an appointment scheduler, on vaccination intentions and uptake within 30 days of the intervention. They

\footnotetext{
${ }^{10}$ Mills and Rüttenauer estimate about 4 mln additional vaccinations in Italy and about 8.6 mln in France for the period 20 days before to 40 days after mandate implementation.

${ }^{11}$ When using total vaccinations instead of first doses, we also do not find a statistically significant effect for Germany.

${ }^{12}$ The interval between mandate announcement and implementation in the ten Canadian provinces and three countries in our sample varies from 5 to 41 days.
} 
find that none of the financial or behavioural treatments increased the vaccination rate among the treated. The proof-of-vaccination mandates we analyze target a similar group of unvaccinated people that have had the opportunity to be vaccinated for a long time. The population-weighted average first-dose vaccination rate on the dates of the provincial mandate announcements is $83.3 \%$, even higher than in Chang et al. (2021), suggesting that financial or behavioural incentives are even less likely to be effective in our setting. ${ }^{13}$ On behavioral nudges, see also Dai et al. (2021), Alsan and Eichmeyer (2021) and Kluver et al. (2021). On financial incentives, see Barber and West (2021), Brehm et al. (2021), Sehgal (2021), and Walkey et al. (2021) on Ohio's vaccine lottery, with mixed results.

\section{Data}

\subsection{Data sources and definitions}

We use data on COVID-19 vaccination numbers, cases and deaths for all ten Canadian provinces, as well as for France, Italy, Germany and Spain. ${ }^{14}$ Announcement and implementation dates of the proof of vaccination mandates were collected from the respective government websites and major newspapers (see Table C1).

The main variables in our statistical analysis are defined below. Everywhere, $i$ denotes province or country and $t$ denotes time measured in days (date). We aggregate the data on vaccinations, cases and deaths on a weekly basis (totals for the week ending on date $t$, i.e., dates $t-6$ to $t$ ) to reduce the influence of day-of-the-week effects and reporting artifacts. ${ }^{15}$

Outcome, $V_{i t}$. Our main outcome variable is the logarithm of administered vaccine first doses per 100,000 people, $V_{i t}$, for the week ending at $t$ (dates $t-6$ to $t$ ). We use first doses as they most directly reflect the impact of proof of vaccination mandates on the intent to be immunized. ${ }^{16}$ Using the logarithm of weekly first doses allows us to interpret the regression coefficients as percentage changes in the outcome; moreover, the estimates are invariant

\footnotetext{
${ }^{13}$ In an RCT study in Sweden, Campos-Mercade et al. (2021) find that a modest payment of SEK 200 (USD 24) is associated with a 4.2 p.p. increase in vaccinations, relative to a baseline rate of $71.6 \%$ in the control group, while none of three behavioral nudges had impact. However, the RCT subjects were yet to become eligible to be vaccinated, and hence the setting is not comparable to ours in which weeks have elapsed after widespread vaccine availability.

${ }^{14}$ See Table $\mathrm{C} 4$ for the data sources and details. We collected the Canadian data from the official provincial dashboards or equivalent sources. We use the Our World In Data dataset for the country data.

${ }^{15}$ Some locations, e.g., British Columbia and Nova Scotia, do not report vaccination data on weekends and then report the total for several days at once (e.g., Monday's number contains 3 days of data). In these cases, we distribute the reported total equally over the affected days.

${ }^{16}$ In Table A4, we also report results using second doses as the outcome. We find no statistically significant effect on second-dose uptake following the announcement of mandate.
} 
to normalization, e.g., by population, as its effect is subsumed in the regression constant or fixed effects. We thus use "log weekly first doses" for simplicity throughout the paper, except where the actual scale is important.

Policy, $P_{i t}$. Let $\hat{t}_{i}$ be the announcement date of the proof of vaccination mandate in jurisdiction $i$. We construct a binary policy variable $P_{i t}$ equal to 1 for all post-announcement dates $t \geq \hat{t_{i}}$ and equal to 0 for all $t<\hat{t_{i}}$. Proof of vaccination mandates were announced in all ten Canadian provinces over the period August 5, 2021 to September 21, 2021 (see Table $\mathrm{C} 1$ and Fig. B3). ${ }^{17}$ The last six provinces to act were the four Atlantic provinces, which had the lowest per capita case rates in August 2021, and Alberta and Saskatchewan, which had the highest per capita case rates in August 2021. Several European countries, including France, Italy and Germany, also introduced proof of vaccination mandates in summer 2021 (see Table C1).

Information, $I_{i t}$. We construct variables related to the underlying COVID-19 epidemiological situation, specifically log of weekly cases, $C_{i t}$, and $\log$ of weekly deaths, $D_{i t}$, for the week ending at date $t$ (dates $t-6$ to $t$ ). ${ }^{18}$ We refer to these variables jointly as information, $I_{i t}$, (see Chernozhukov et al., 2021 or Karaivanov et al., 2021) since they can inform a person's COVID-19 exposure risk assessment and/or decision to be vaccinated. ${ }^{19}$

Controls, $W_{i t}$. We include province fixed effects and date fixed effects in our panel data analysis. The province fixed effects account for any time-invariant province characteristics such as sentiment towards vaccination, age distribution, etc. The date fixed effects control for nation-wide trends or events, e.g., public messaging, vaccine-related international travel regulations, or political campaigning for the September 2021 federal election. In the timeseries analysis, we control for time trends.

Time period. We use the period June 15, 2021 to October 31, 2021. The start date is chosen to ensure that possible constraints to obtain a first dose related to eligibility or vaccine supply are minimal or non-existent. ${ }^{20}$ We explore different sample start dates in robustness

\footnotetext{
${ }^{17}$ We use Sep. 17, 2021 as the mandate announcement date for Newfoundland and Labrador, the date on which the premier (provincial head of government) announced the upcoming mandate. The mandate details were officially unveiled on Oct. 7 after consultations with the business and other sectors. However, using the latter date would be problematic because of a potentially strong anticipation effect following the first announcement. Our main results in Table 1 and Fig. 3 are not affected by this choice. Throughout the paper, "Newfoundland" refers to the province of Newfoundland and Labrador.

${ }^{18}$ Another possible information variable is hospitalizations. However, it is very strongly correlated with the COVID-19 cases and deaths. To avoid multicollinearity, we do not include it in our baseline specification. See Table A2 for results using deaths and hospitalizations as information instead of deaths and cases.

${ }^{19}$ To tackle zero weekly values, which sometimes occur in the smaller provinces for deaths or cases $(4.4 \%$ of all observations for cases and $10.7 \%$ for deaths), we replace $\log (0)$ with -1 as in Chernozhukov et al. (2021).

${ }^{20}$ In Canada, the provinces opened registration for first-dose vaccination for any person of age $12+$ between May 10, 2021 in Alberta and May 27, 2021 in Nova Scotia, see Table C2. First-dose availability in France,
} 
checks. The sample end date is based on data availability at the time of statistical analysis and writing. First doses for the 5-11 age group were not approved in this period.

Figure 2: First doses after mandate announcement
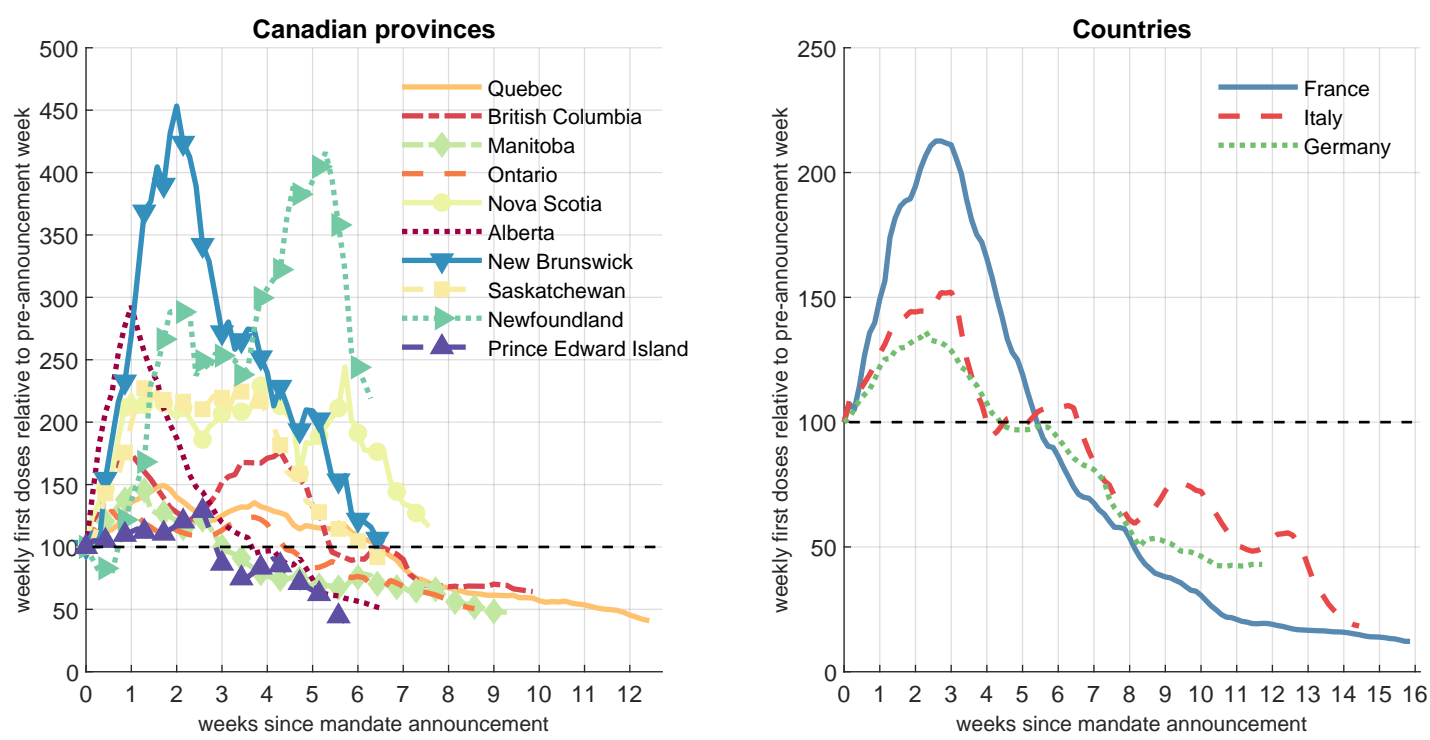

Notes: The figure plots the weekly administered first doses of COVID-19 vaccine for all dates after the mandate announcement against the number of weeks since the respective announcement date (denoted by 0 on the horizontal axis), as of Oct. 31, 2021. The weekly first doses for the week just prior to the mandate announcement are normalized to 100 for each respective province (on the left) or country (on the right).

\subsection{Descriptive analysis}

Fig. 2 plots the time profile of weekly first doses after a mandate announcement, with first doses in the week ending on the mandate announcement date normalized to 100. The figure only provides a raw-data illustration of the magnitude of the increase in weekly first doses following a mandate announcement. We follow up with formal analysis, controlling for information, fixed effects, pre-trends and other factors, in Sections 3-5.

Fig. 2 shows that weekly first doses in the Canadian provinces and in France, Italy and Germany grow quickly after the proof of vaccination mandate announcement, reach a peak at about 1 to 3 weeks after the announcement date and then decrease, as in the preannouncement trend in most locations (see Fig. B4). ${ }^{21}$ Several provinces, notably New Brunswick, Newfoundland, Alberta, Nova Scotia and Saskatchewan, as well as France, registered large increases in first-dose vaccine uptake of over $100 \%$ relative to the pre-

Italy and Germany was similar by mid-June, at least for the 18+ age group.

${ }^{21}$ British Columbia, Ontario, Nova Scotia, Saskatchewan and Newfoundland exhibit a second peak later. 
medRxiv preprint doi: https://doi.org/10.1101/2021.10.21.21265355; this version posted January 13, 2022. The copyright holder for this preprint (which was not certified by peer review) is the author/funder, who has granted medRxiv a license to display the preprint in perpetuity.

All rights reserved. No reuse allowed without permission.

announcement week. In other locations, e.g., Quebec, Ontario, Manitoba and Germany the observed increase is more moderate (less than 50\%).

\section{Panel data results - Canadian provinces}

\subsection{Estimation}

We estimate a behavioral model in which the decision to receive a COVID-19 vaccine (measured by new weekly first doses) is affected by the policy setting, $P_{i t}$ (whether a proof of vaccination mandate has been announced) and the current COVID-19 epidemiological and public health conditions, $I_{i t}$, proxied by weekly cases and deaths. Based on the raw data patterns in Fig. 1 and Fig. B4 and the absence of vaccine supply constraints in the studied period, we assume no lag between the mandate announcement and a person's ability to receive a first vaccine dose. ${ }^{22}$ Finally, we assume that individuals take into account the weekly public health indicators, $I_{i t}$, for the week ending at date $t$, with no lag.

We use a difference-in-differences (DID) method to study the average effect of proof of vaccination mandates in Canada. In addition to information $I_{i t}$, we control for other potential confounding variables or unobserved heterogeneity by including time and location fixed effects. We estimate the following equation:

$$
V_{i t}=\alpha P_{i t}+\beta I_{i t}+\gamma_{t}+\delta_{i}+\varepsilon_{i t}
$$

where $V_{i t}$ is $\log$ weekly first doses for location $i$ and date $t, I_{i t}$ is information, $\gamma_{t}$ are date fixed effects, $\delta_{i}$ are province fixed effects, and $\varepsilon_{i t}$ is the error term. The coefficient $\alpha$ on the policy variable $P_{i t}$ captures the average effect of the mandate announcement on weekly first doses over all post-announcement dates. To capture dynamic effects of the mandates, we also estimate a version of equation (1) with $P_{i t}$ broken into separate indicator variables, one for each week after the mandate announcement date. To correct for the small number of clusters in the estimation due to there being only ten provinces, we compute and report "wild bootstrap" p-values (Cameron et al., 2008). ${ }^{23}$

The recent methodological literature has argued that the standard OLS two-way fixed effects (TWFE) estimator can be invalid in panel-data settings with staggered adoption like ours if there is heterogeneity in the treatment effect across groups/cohorts (provinces in this

\footnotetext{
${ }^{22}$ For our main model (difference-in-differences), we perform sensitivity analysis using alternative lags of up to 7 days (see Section 3.3 and Fig. B5); the results affirm our baseline choice of zero lag.

${ }^{23}$ We use the Stata function boottest (see Roodman et al., 2019) clustered by province with 4,999 repetitions. Alternative ways of computing the standard errors are displayed in Table A3.
} 
medRxiv preprint doi: https://doi.org/10.1101/2021.10.21.21265355; this version posted January 13, 2022. The copyright holder for this preprint (which was not certified by peer review) is the author/funder, who has granted medRxiv a license to display the preprint in perpetuity.

All rights reserved. No reuse allowed without permission.

paper) and/or over time. The reason is that the TWFE estimate is a weighted average of many 2-by-2 DID treatment effects, where some of the weights can be negative or incorrect because of contamination from other periods (Goodman-Bacon, 2021). ${ }^{24}$ In particular, Sun and Abraham (2021) develop an 'interaction-weighted' difference-in-differences estimator that is valid under these conditions and which we use to estimate (1). The Sun and Abraham estimator uses never-treated or last-treated units as the control group and is constructed as an appropriately weighted average of treatment effects for each cohort (by date of mandate announcement) and each relative time after or before the announcement. ${ }^{25}$

The Sun-Abraham estimator requires excluding from the estimation all time periods in which units in the control group are treated. Since the last province to announce a mandate is Prince Edward Island, on September 21, 2021, this means that we can use only data until September 20, at the latest (see Table C1). We present results for different control groups and corresponding sample periods in Table A1. We also compare our baseline results with the OLS TWFE estimates in Table A2. In addition, in Section 4 we report results from time-series analysis using all available data until October 31.

\subsection{Results}

Fig. 3 displays an event study analysis of weekly first doses administered in the ten Canadian provinces, from six weeks before to five or more weeks after the announcement of a proof of vaccination mandate. $T=0$ denotes the week starting at the announcement date. The reference point is one week before the mandate announcement $(T=-1)$. We use the Sun and Abraham (2021) treatment effect heterogeneity robust estimator and use as the control group (latest treated) the last five provinces to announce a mandate (Alberta, New Brunswick, Saskatchewan, Newfoundland and Prince Edward Island). We chose this control group as the latest-in-time representative set of provinces containing a mix of smaller and larger provinces by population. The control group implies September 14, 2021 (the day before mandate announcement in Alberta and New Brunswick, see Table C1) as the (latest possible) sample end date in our baseline specification. We present results with different control groups, corresponding to both earlier and later end dates, in Table A1.

We make several observations on Fig. 3. First, there is no mandate-associated pre-trend - the Sun-Abraham DID estimates before the mandate announcement are statistically indistinguishable from zero. This addresses the potential endogeneity concern that provinces

\footnotetext{
${ }^{24}$ See also Athey and Imbens (2018), de Chaisemartin and D'Haultfoeuille (2018), Callaway and Sant'Anna (2021) and Sun and Abraham (2021).

${ }^{25}$ We use the Stata function eventstudyinteract provided by the authors.
} 
Figure 3: Canadian provinces - event study

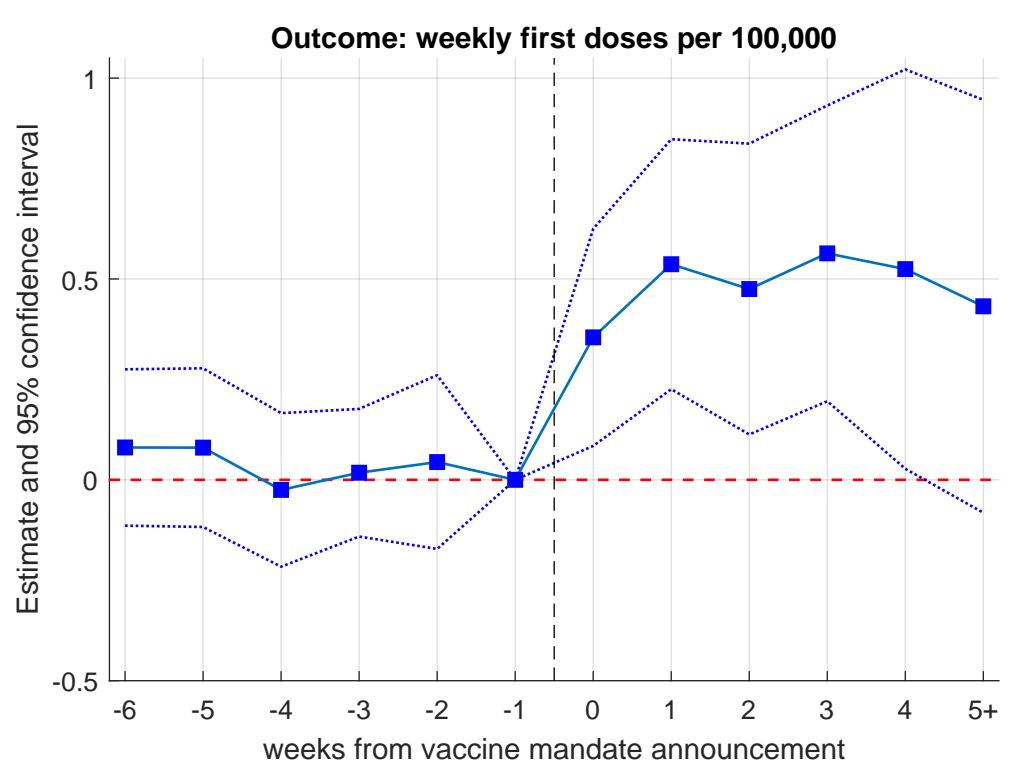

Notes: Sun and Abraham (2021) treatment effect heterogeneity robust estimates. Sample period: June 15 to September 14, 2021 using Alberta, New Brunswick, Saskatchewan, Prince Edward Island and Newfoundland as the control group (latest treated). The outcome variable, $V_{i t}$ is $\log$ weekly first doses per 100,000 people administered for dates $t-6$ to $t$ inclusive. The figure plots the estimates from a variant of equation (1) where the mandate announcement variable $P_{i t}$ is replaced by the interaction of being in the 'treatment' group (announced mandate) with a series of dummies for each week ranging from 6 weeks before $(T=-6)$ to 5 or more weeks after the announcement $(T=5)$, where $T=0$ is the week of the announcement. The reference point is one week before the announcement $(T=-1)$. The dotted lines correspond to $95 \%$ confidence intervals.

that announced a mandate may have had a different trend in first-dose vaccinations than provinces that did not announce a mandate. Second, the impact of the mandate announcement on first-dose vaccine uptake is realized relatively quickly. Third, the mandate effect on the pace of first-dose vaccinations is large in magnitude - an increase of $42 \%$ (35 log points, CI 9-62) in weekly first doses in the first post-announcement week and $71 \%$ (54 log points, 21-86) in the second week, each relative to one week before the announcement. ${ }^{26}$ The observed quick increase in uptake mitigates possible concerns that vaccine supply or scheduling constraints may be affecting our results (see also Fig. 2 for a raw data plot of the post-announcement increase in first-dose vaccinations by province). Fourth, the average policy effect persists over time over the 6 -week post-announcement period we analyze $(T=0$ to $T=5$ ). Unfortunately, the limitations of the data (the timing of the announcements) and the need for a not-yet-treated control group do not allow us to investigate longer horizons.

\footnotetext{
${ }^{26}$ A coefficient estimate $x$ is equivalent to $100 x$ log points or a $100\left(e^{x}-1\right)$ percent increase in weekly doses. The smaller $T=0$ estimate reflects the fact that the outcome variable is a backward-looking weekly sum.
} 
We return to this in Section 4 using time-series analysis of all the data until October 31.

Table 1: Canadian provinces - difference-in-differences results

\begin{tabular}{|c|c|c|c|}
\hline \multicolumn{4}{|c|}{ Outcome: log weekly vaccine first doses, $V_{i t}$} \\
\hline $\mathrm{p}$-values in [] & $(1)$ & $(2)$ & $(3)$ \\
\hline mandate announced, $P_{i t}$ & $\begin{array}{l}0.504 * * * \\
{[0.002]}\end{array}$ & $\begin{array}{l}0.506 * * * \\
{[0.001]}\end{array}$ & \\
\hline week 0 & & & $\begin{array}{l}0.359 * * * \\
{[0.005]}\end{array}$ \\
\hline week 1 & & & $\begin{array}{l}0.543 * * * \\
{[0.001]}\end{array}$ \\
\hline week 2 & & & $\begin{array}{l}0.498 * * \\
{[0.010]}\end{array}$ \\
\hline week 3 & & & $\begin{array}{l}0.705 * * * \\
{[0.001]}\end{array}$ \\
\hline week 4 & & & $\begin{array}{l}0.713 * * \\
{[0.018]}\end{array}$ \\
\hline week $5+$ & & & $\begin{array}{l}0.651 * \\
{[0.056]}\end{array}$ \\
\hline $\log$ weekly cases, $C_{i t}$ & & $\begin{array}{l}0.002 \\
{[0.967]}\end{array}$ & $\begin{array}{l}0.002 \\
{[0.958]}\end{array}$ \\
\hline log weekly deaths, $D_{i t}$ & & $\begin{array}{l}0.048 \\
{[0.365]}\end{array}$ & $\begin{array}{l}0.046 \\
{[0.415]}\end{array}$ \\
\hline R-squared & 0.817 & 0.820 & 0.821 \\
\hline sample size, $\mathrm{N}$ & 920 & 920 & 920 \\
\hline province fixed effects & X & $\mathrm{X}$ & $\mathrm{X}$ \\
\hline date fixed effects & $\mathrm{X}$ & $\mathrm{X}$ & $\mathrm{X}$ \\
\hline
\end{tabular}

Notes: Sun and Abraham (2021) treatment effect heterogeneity robust estimates. Sample period: June 15 to September 14, 2021 using Alberta, New Brunswick, Saskatchewan, Prince Edward Island and Newfoundland as control group (latest treated). "week $\mathrm{n}$ ", where $n=0,1,2, \ldots$, is a binary variable that takes value 1 for the days in the $\mathrm{n}$-th week immediately after the announcement date (week 0 is the week starting at the announcement date) and value 0 otherwise. The $C_{i t}$ and $D_{i t}$ variables are log weekly totals for dates $t-6$ to $t$. P-values from wild bootstrap (boottest) standard errors clustered by province with 4,999 repetitions are reported in the square brackets. $*$, ** and *** denote $10 \%, 5 \%$ and $1 \%$ significance respectively. The results in column (3) are not directly comparable to those in Fig. 3 because in Table 1 the reference point is the entire pre-announcement period.

Table 1 shows the Sun-Abraham DID estimates of equation (1) along with p-values from wild bootstrap standard errors clustered by province in the square brackets. ${ }^{27}$ Columns (1)

\footnotetext{
${ }^{27}$ In Table A3 we also report alternative standard error specifications: regular clustering at the province level (Stata command "cluster"), wild bootstrap standard errors clustered at the province level (Stata command "boottest") and wild bootstrap standard errors two-way clustered by province and date.
} 
medRxiv preprint doi: https://doi.org/10.1101/2021.10.21.21265355; this version posted January 13, 2022. The copyright holder for this preprint (which was not certified by peer review) is the author/funder, who has granted medRxiv a license to display the preprint in perpetuity.

All rights reserved. No reuse allowed without permission.

and (2) (without and with controlling for weekly cases and deaths) show that the mandate announcement is associated with an average increase of about 66 percent (50.6 log points, CI 25-77 in column 2) in weekly first doses. In column (3) of Table 1, we report estimates from a variant of equation (1) where the policy variable $P_{i t}$ is decomposed into six binary variables (one for each week after the announcement date) to account for dynamic effects. The results indicate a sharp increase in weekly first doses of 43 percent (36 log points, CI $14-58, p<0.01$ ) in the week beginning at the announcement date (week 0 ). The increase is sustained until the sample end date as all estimates in column $(3)$ are positive $(p<0.02$, except for "week 5+", $p<0.06$ ) and larger than in week 0 . We note that the later estimates are based primarily (week 3) or only (week 4) on post-mandate vaccinations in Quebec, the province with the earliest announcement. Thus, the DID analysis yields no evidence that short-term net intertemporal substitution (which would be manifested as a negative policy estimate for the later weeks) is the mechanism behind the observed boost in vaccinations in the studied period.

In Table A1, reporting policy estimates by week after announcement and the upper left panel of Fig. B5, reporting the average estimate for the post-announcement period, we use different sets of provinces as control group, from only Prince Edward Island (PEI) (using data up to Sep. 20), to all provinces except Quebec, British Columbia and Manitoba (using data up to Aug. 31). We find that our main results from Table 1 remain robust to using alternative control groups.

\subsection{Robustness analysis}

Alternative initial dates. In Fig. B5, upper right panel, we show that our estimates of the effect of a mandate announcement on first dose vaccine uptake are not very sensitive to the choice of initial sample date between May 1 and Jul. 15, 2021. This provides further reassurance that vaccine supply constraints are not a major concern for our results.

Lags. In equation (1), we assume no lag between the mandate announcement $P_{i t}$ and a person's ability to receive the first dose (the outcome $V_{i t}$ ). In practice, a small delay may occur (e.g., from making an appointment to receiving the vaccine) even in the absence of supply constraints. The lower left panel of Fig. B5 displays the coefficient estimates $\hat{\alpha}$ of the policy effect when assuming a lag of zero (our baseline) to seven days. The mandate effect estimates remain large and statistically significant when varying the lag length, with a slight decrease for the longer lags. The lower right panel of Fig. B5 displays the policy estimates $\hat{\alpha}$ when assuming a lag of zero (our baseline) to 14 days in the information variables $I_{i} t$ 
(log weekly cases and deaths). The mandate effect estimates remains large and statistically significant when varying the lag length. ${ }^{28}$

Other robustness checks. We perform additional robustness checks in Table A2. For easier comparison, column (1) replicates our baseline estimates from columns (2) and (3) of Table 1. Column (2) of Table A2 omits cases and deaths, the coefficients for which are not significant in the baseline specification. In column (3), we control for log weekly deaths and log average weekly hospitalizations as information. Column (4) reports the estimates of a weighted specification using the provincial populations as weights and the baseline information variables (cases and deaths). The estimates are smaller than in the unweighted baseline (column 1), suggesting that smaller provinces contribute more to the the estimated effect of mandate announcements on vaccine uptake. In column (5), we re-estimate equation (1) using the standard OLS two-way fixed effects (TWFE) estimator which, as discussed in Section 3.1, can be biased in the presence of heterogeneous treatment effects over cohorts and/or time. In our setting, we find that these estimates differ relatively little from our baseline Sun-Abraham treatment effect heterogeneity robust estimates.

In Table A2 column (6), we use log of daily (instead of weekly) first doses as the outcome and $\log$ of daily cases and deaths as information and find similar estimates to those in our baseline specification, although larger in week 0 since the outcome is not a moving sum. In column (7), we use the level of weekly first doses per 100,000 people as the outcome. The estimates are noisier than in the baseline and indicate that a mandate announcement increases weekly first dose uptake by roughly 482 per 100,000 people on average (CI -11$975, p<0.06)$ after the announcement. Overall, all these alternative specifications confirm the robustness of our main finding of statistically significant and large impact of mandate announcements on vaccine uptake.

Randomization inference. Difference-in-differences inference from the model in equation (1) relies on asymptotic approximations requiring a sufficiently large number of provinces. While we do account for the fact that there are only 10 provinces in our sample by using wild bootstrap to compute the estimates' p-values, as an additional robustness check, we implement a variant of Fisher's randomization test (Fisher, 1935). Specifically, we estimate equation (1) 5,000 times by randomly assigning the mandate announcement date for each of the 'treated' provinces in our baseline specification. Fig. B6 plots the histogram of the randomized inference (placebo) mandate effect estimates, along with the $95 \%$ confidence band. Only $2.88 \%$ of the 5,000 placebo estimates are larger than our baseline estimate 0.506

\footnotetext{
${ }^{28}$ We also checked a specification in which we lag the information variables $I_{i t}$ (log weekly cases and deaths) with the same lag as the policy $P_{i t}$, and the results are nearly identical.
} 
medRxiv preprint doi: https://doi.org/10.1101/2021.10.21.21265355; this version posted January 13, 2022. The copyright holder for this preprint (which was not certified by peer review) is the author/funder, who has granted medRxiv a license to display the preprint in perpetuity.

All rights reserved. No reuse allowed without permission.

from column (2) of Table 1 (the solid vertical line on Fig. B6), offering assurance that our main result does not hinge on asymptotic inference.

\subsection{Second doses}

In Table A4, we estimate the specifications in Table 1 using log of weekly second doses as the outcome. There are two potential mechanisms through which proof of vaccination mandates may have an impact on second dose uptake: (i) people that already had a first dose decide to receive their second dose soon after the announcement or implementation (e.g., because most mandates require full vaccination) and (ii) people that took a first dose because of the mandate take their second dose roughly 4 weeks after the first. We do not find a statistically significant effect of mandate announcements on second dose uptake in our sample period. This is consistent with second doses being more spread out after the announcement. We also plot weekly second doses over time on Fig. B7 and, unlike the sharp increases for first doses, we only see relatively small and gradual second-dose increases after the mandate announcements in some of the (smaller) provinces.

\subsection{Mandate implementation}

Our main results use the regional variation in the timing of announcement of proof of vaccination mandates to examine their effect on vaccine uptake. In addition, there is variation in the interval between the mandates' announcement and implementation (coming into force), as well as in the implementation dates themselves - see Table C1 and Fig. B4. ${ }^{29}$ We checked whether we can detect additional effects on first-dose uptake, associated with the mandates' implementation, by adding to equation (1) an indicator variable that equals to 1 postimplementation and 0 otherwise. The estimate on this indicator variable is positive but not statistically significantly different from zero (not displayed). However, we cannot conclude that there do not exist implementation effects, since even the latest feasible sample end date (Sep. 20, 2021) necessitated by the requirement to have a not yet treated control group is only soon after the mandate implementation date in 3 of the 10 provinces (see Table C1).

\footnotetext{
${ }^{29}$ The mandates were implemented in all provinces between Sep. 3 and Oct. 22, 2021.
} 


\section{$4 \quad$ Time series analysis}

\subsection{Estimation method}

We complement and extend our panel data analysis for Canada by time-series analysis for each of the ten Canadian provinces, as well as for France, Italy and Germany. While the Sun and Abraham (2021) difference-in-differences approach in Section 3 allows us to reliably estimate the impact of mandate announcements on new first doses in Canada by exploiting the variation in the timing of the mandates across provinces, it can only be used with data from before the last treatment date and hence it does not allow us to evaluate the effect of the mandates beyond the short term. In contrast, under stronger identification assumptions, the time-series approach allows us to use all our data until October 31, 2021 to estimate the mandates' effect on vaccine uptake and the cumulative additional vaccinations compared to the counterfactual of no mandate separately for each province and country.

We use the 'interrupted time-series analysis' (ITSA) framework (e.g., Linden, 2015) and estimate the following equation for each country or province ${ }^{30}$

$$
V_{t}=c+\lambda_{1} V_{t-7}+\lambda_{2} V_{t-14}+\pi P_{t}+\tau_{1} T_{t}+\tau_{2} T_{t}^{a}+\mu I_{t}+\eta_{t}
$$

where $V_{t}$ are log weekly first doses for the week ending at date $t, c$ is a constant, $I_{t}$ is proxy for information analogous to its counterpart in equation (1), and $\eta_{t}$ is the error term. In our baseline time-series specification, we construct the policy variable $P_{t}$ as the weekly average from date $t-6$ to $t$ of the 'mandate announced' indicator $P_{i t}$ defined in Section 2.1. ${ }^{31} \mathrm{We}$ include 7-day and 14-day lagged values of $V_{t}$ (instead of $t-1$ or $t-2$ autoregressive terms) since the outcome variable $V_{t}$ is a weekly total.

We include two time trends in equation (2): $T_{t}$ is a linear daily time trend initialized at the sample start date $t=0$ and $T_{t}^{a}$ is an 'interaction' time trend which takes value 0 at all dates until the announcement date (inclusive) and increases by 1 for each day afterwards. The coefficients $\tau_{1}$ (slope) and $\tau_{2}$ (change in slope at the announcement date) characterize respectively the baseline (pre-announcement) time trend and the post-announcement time trend (with slope $\tau_{1}+\tau_{2}$ ) in weekly first doses.

The time-series estimation requires stronger identifying assumptions than the DID approach since there is no control group. Specifically, we need to assume that the time-series

\footnotetext{
${ }^{30}$ We omit the subscripts $i$ for simplicity since all variables refer to the same location.

${ }^{31}$ Using a weekly average of the mandate indicator is consistent with the weekly vaccination and information variables $V_{t}$ and $I_{t}$ and improves the fit in the time-series regressions. We also present results without weekly averaging in Tables A6 and A7.
} 
medRxiv preprint doi: https://doi.org/10.1101/2021.10.21.21265355; this version posted January 13, 2022. The copyright holder for this preprint (which was not certified by peer review) is the author/funder, who has granted medRxiv a license to display the preprint in perpetuity.

All rights reserved. No reuse allowed without permission.

process of weekly first doses changed after the mandate announcement only because of the policy, i.e., that it would have followed the same pre-trend if no mandate had been announced. Another needed assumption is exogeneity of the announcement date. We also cannot control for fixed effects in a flexible way beyond including a constant and time trends. Under these assumptions, the coefficient on the policy variable $P_{t}$ captures the average level shift in first-dose uptake attributed to the mandate announcement. Similarly, the coefficient on the interaction time trend $T_{t}^{a}$ measures the slope change in the time trend of first doses after the mandate announcement, relative to the pre-announcement trend.

\subsection{Structural break at the mandate announcement date}

We first show the impact of the proof of vaccination mandate announcements on first dose uptake in Table A5, where we perform a structural break test (Chow (1960) test for a known break point) for the log weekly first doses, $V_{t}$. The presence of a break point in $V_{t}$ at the mandate announcement date indicates an abrupt change (shift) in the first-dose time series process. We use a bandwidth of 50 days before and 35 days after the mandate announcement date. ${ }^{32}$ The before-after bandwidth was chosen to reduce the size distortion of the test since the outcome variable is a weekly sum and the error terms are serially correlated. ${ }^{33}$ Columns (1) and (2) in Table A5 use the log of weekly first doses, $V_{t}$. For all ten Canadian provinces and all three countries, we strongly reject the null hypothesis that the mandate announcement date is not a structural break $(p<0.01)$.

We also perform the structural break test using first-differenced weekly first doses in Table A5 column (3). The differenced series is stationary, and the error terms are not serially correlated, which alleviates concerns about size distortion in the Chow test. The null hypothesis of no structural break at the announcement date is rejected with $p<0.05$ in most locations except Saskatchewan and three Atlantic provinces. ${ }^{34}$ Overall, the structural break test results suggest that a mandate announcement is strongly associated with a trend break in first-dose vaccine uptake in all or most locations depending on the specification.

\footnotetext{
${ }^{32}$ The results are also robust to picking June 15, 2021 as the initial date for the test.

${ }^{33}$ As shown in Giles and Scott (1992), the size of the Chow test is distorted upward (over-rejection of the null) in the presence of positive serial correlation in the error terms. The size distortion is mitigated if the sample split is unequal before vs. after the break point.

${ }^{34}$ The power of the Chow test is weaker in this specification since the first-differenced $V_{t}$ series is a growth rate being used to test for a level shift. The differenced series is also noisier as it captures daily fluctuations.
} 
medRxiv preprint doi: https://doi.org/10.1101/2021.10.21.21265355; this version posted January 13, 2022. The copyright holder for this preprint (which was not certified by peer review) is the author/funder, who has granted medRxiv a license to display the preprint in perpetuity.

All rights reserved. No reuse allowed without permission.

\subsection{Results}

In Table 2, we report the results from estimating the time-series model (2) for each country and province in our data. ${ }^{35}$ We include log weekly cases and deaths as information, $I_{t}$. In columns (1)-(3), we report the estimated coefficients on the mandate announcement variable, $P_{t}$, the time trend, $T_{t}$, and the interaction time trend, $T_{t}^{a}$, in equation (2). Since the outcome and information variables are level variables that can introduce non-stationarity, we use the augmented Dickey-Fuller (ADF) unit root test to test whether the residuals $\eta_{t}$ are stationary, to avoid a spurious regression. ${ }^{36}$ We reject the null hypothesis that the residual contains a unit root at the $95 \%$ confidence level for all locations except Newfoundland, where we can reject the null at the $90 \%$ level.

The coefficient estimates $\hat{\pi}$ on the mandate announcement variable $P_{t}$ in Table 2 are large and statistically significantly positive $(p<0.01)$ for all three countries. Italy's estimated initial rise in weekly first doses after the mandate announcement is the largest (102.5 log points, CI 53-152), i.e., $179 \%$ average increase relative to the pre-announcement trend, followed by Germany (43.8 log points, CI 31-56 or 55\% increase) and France (15.4 log points, CI 5-26 or $17 \%$ increase). ${ }^{37}$ The baseline time trend is downward sloping $\left(\hat{\tau}_{1}<0\right)$ in all countries and indicates a steep decrease in vaccinations of $1.7 \%$ to $2.9 \%$ per day. The post-announcement trend in first doses turns less steep in all three countries (the post-announcement slope change estimate $\hat{\tau_{2}}$ is positive, although only statistically significant for Germany), which suggests a lack of net intertemporal substitution as of October 31.

Turning to the Canadian provinces in Table 2 we obtain statistically significantly positive and large estimates of the increase in weekly first doses after mandate announcement, $\hat{\pi}$ for all provinces except Quebec. ${ }^{38}$ The statistically significant policy estimates range from 0.293 (0.082-0.505) in Ontario, equivalent to a 34\% average increase in first doses relative to the pre-announcement trend, to 1.455 (1.102-1.808) in Alberta (a 328\% increase). The range of estimates is consistent with our DID estimate in Table 1 for the average policy effect for Canada, although the two estimation methods are not directly comparable.

\footnotetext{
${ }^{35}$ The estimates' p-values are calculated using the Newey-West heteroskedasticity and autocorrelation (HAC) robust estimator (Newey and West, 1987) with 3 lags. The lag length was chosen as the closest integer to $T^{1 / 4}$, where $T$ is the sample size.

${ }^{36}$ The ADF test results in column (4) use 13 lags, chosen as the integer part of $12(T / 100)^{1 / 4}$, see Schwert (1989). For fewer lags the test tends to yield smaller p-values.

${ }^{37}$ France's estimate is sensitive to including log weekly cases. We obtain a larger estimate, $\hat{\pi}=0.468$ (0.326-0.610), or $60 \%$ increase, using deaths and hospitalizations as information variables, see Table A6.

${ }^{38}$ The estimate for Quebec is $0.389(0.265-0.514)$ and statistically significantly different from zero when we use deaths and hospitalizations as information $I_{t}$; see Table A6.
} 
Table 2: Time series estimates

\begin{tabular}{|c|c|c|c|c|}
\hline p-values in [] & $\begin{array}{c}\text { policy } \hat{\pi} \\
(1)\end{array}$ & $\begin{array}{l}\text { vaccine first } \\
\text { time } \\
\text { trend } \hat{\tau}_{1} \\
\quad(2)\end{array}$ & $\begin{array}{l}\text { doses } \\
\text { trend } \\
\text { change } \hat{\tau}_{2} \\
(3)\end{array}$ & $\begin{array}{c}\text { ADF test } \\
(4)\end{array}$ \\
\hline \multicolumn{5}{|l|}{ Countries } \\
\hline France & $\begin{array}{l}0.154 \text { *** } \\
{[0.004]}\end{array}$ & $\begin{array}{l}-0.018 \text { *** } \\
{[0.000]}\end{array}$ & $\begin{array}{l}0.003 \\
{[0.229]}\end{array}$ & $\begin{array}{l}-3.970 \\
{[0.002]}\end{array}$ \\
\hline Italy & $\begin{array}{l}1.025 \text { *** } \\
{[0.000]}\end{array}$ & $\begin{array}{l}-0.029 * * * \\
{[0.001]}\end{array}$ & $\begin{array}{l}0.005 \\
{[0.556]}\end{array}$ & $\begin{array}{l}-3.365 \\
{[0.012]}\end{array}$ \\
\hline Germany & $\begin{array}{l}0.438 \text { *** } \\
{[0.000]}\end{array}$ & $\begin{array}{l}-0.017 \text { *** } \\
{[0.000]}\end{array}$ & $\begin{array}{l}0.006 \text { ** } \\
{[0.012]}\end{array}$ & $\begin{array}{l}-3.235 \\
{[0.018]}\end{array}$ \\
\hline \multicolumn{5}{|l|}{ Canadian provinces } \\
\hline Quebec & $\begin{array}{l}0.064 \\
{[0.647]}\end{array}$ & $\begin{array}{l}-0.029 * * \\
{[0.010]}\end{array}$ & $\begin{array}{l}0.017 * \\
{[0.079]}\end{array}$ & $\begin{array}{l}-5.192 \\
{[0.000]}\end{array}$ \\
\hline British Columbia & $\begin{array}{l}0.734 * * * \\
{[0.000]}\end{array}$ & $\begin{array}{l}-0.013 \text { *** } \\
{[0.008]}\end{array}$ & $\begin{array}{l}-0.004 \\
{[0.400]}\end{array}$ & $\begin{array}{l}-4.587 \\
{[0.000]}\end{array}$ \\
\hline Manitoba & $\begin{array}{l}0.757 * * * \\
{[0.000]}\end{array}$ & $\begin{array}{l}-0.034 \text { *** } \\
{[0.000]}\end{array}$ & $\begin{array}{l}0.012^{* *} \\
{[0.014]}\end{array}$ & $\begin{array}{l}-4.735 \\
{[0.000]}\end{array}$ \\
\hline Ontario & $\begin{array}{l}0.293 * * * \\
{[0.007]}\end{array}$ & $\begin{array}{l}-0.011 * * \\
{[0.033]}\end{array}$ & $\begin{array}{l}0.002 \\
{[0.739]}\end{array}$ & $\begin{array}{l}-4.166 \\
{[0.001]}\end{array}$ \\
\hline Nova Scotia & $\begin{array}{l}0.595 \text { *** } \\
{[0.002]}\end{array}$ & $\begin{array}{l}-0.025 \text { *** } \\
{[0.000]}\end{array}$ & $\begin{array}{l}0.021 * * \\
{[0.021]}\end{array}$ & $\begin{array}{l}-4.698 \\
{[0.000]}\end{array}$ \\
\hline Alberta & $\begin{array}{l}1.455 \text { *** } \\
{[0.000]}\end{array}$ & $\begin{array}{l}-0.015 * * * \\
{[0.000]}\end{array}$ & $\begin{array}{l}-0.024 \text { *** } \\
{[0.000]}\end{array}$ & $\begin{array}{l}-3.372 \\
{[0.012]}\end{array}$ \\
\hline New Brunswick & $\begin{array}{l}1.313 \text { *** } \\
{[0.000]}\end{array}$ & $\begin{array}{l}-0.011 * * \\
{[0.019]}\end{array}$ & $\begin{array}{l}-0.017 \text { *** } \\
{[0.004]}\end{array}$ & $\begin{array}{l}-4.416 \\
{[0.000]}\end{array}$ \\
\hline Saskatchewan & $\begin{array}{l}0.898 * * * \\
{[0.000]}\end{array}$ & $\begin{array}{l}-0.008 * * * \\
{[0.001]}\end{array}$ & $\begin{array}{l}-0.013 * * \\
{[0.013]}\end{array}$ & $\begin{array}{l}-3.800 \\
{[0.003]}\end{array}$ \\
\hline Newfoundland & $\begin{array}{l}0.410 * \\
{[0.075]}\end{array}$ & $\begin{array}{l}-0.007 \\
{[0.241]}\end{array}$ & $\begin{array}{l}0.005 \\
{[0.742]}\end{array}$ & $\begin{array}{l}-2.689 \\
{[0.076]}\end{array}$ \\
\hline Prince Edward Island & $\begin{array}{l}0.378 * * \\
{[0.010]}\end{array}$ & $\begin{array}{l}-0.002 \\
{[0.565]}\end{array}$ & $\begin{array}{l}-0.014 \text { ** } \\
{[0.019]}\end{array}$ & $\begin{array}{l}-2.904 \\
{[0.045]}\end{array}$ \\
\hline sample size for each row & 139 & 139 & 139 & 139 \\
\hline
\end{tabular}

Notes: Time period - June 15 to October 31, 2021. Each row is a separate time-series regression as specified in (2). All rows include 7-day and 14-day lags of the outcome variable and log weekly deaths $D_{t}$ and $\log$ weekly cases $C_{i t}$ as information, $I_{t}$. Column (1) reports the estimate $\hat{\pi}$ on the mandate announcement policy variable $P_{t}$ in equation (2). Column (2) reports the estimate $\hat{\tau}_{1}$ on the linear time trend $T_{t}$. Column (3) reports the estimate $\hat{\tau_{2}}$ of the post-announcement trend slope change. $\mathrm{P}$-values computed using Newey-West heteroskedasticity and autocorrelation robust (HAC) standard errors with 3 lags are in the square brackets. ${ }^{*}, * *$ and $* * *$ denote $10 \%, 5 \%$ and $1 \%$ significance respectively. Column (4) reports augmented Dickey-Fuller (ADF) test statistics and p-values using 13 lags (Schwert, 1989). 
The estimated effect of the mandate announcement tends to be larger for provinces experiencing a surge in cases at the same time (for which we control in $I_{t}$ ), namely Alberta, Saskatchewan and New Brunswick. These provinces also announced their mandates relatively late (mid-September) and set a relatively short time interval between mandate announcement and implementation (see Table $\mathrm{C} 1$ ). A larger fraction of eligible unvaccinated people at the time of mandate announcement is also positively associated with a larger policy effect estimate. We illustrate these associations in Fig. B8.

As in the results for the countries, the estimates of the base time trend in first doses, $\tau_{1}$, are negative for all ten provinces (although not statistically significant in the two smallest provinces, Newfoundland and Prince Edward Island). The estimates $\hat{\tau}_{2}$ of the postannouncement change in slope of the time trend are large and statistically significantly negative for Alberta, New Brunswick, Saskatchewan, and PEI (British Columbia's estimate is also negative but not statistically significant). This result is consistent with the mandate effect on new first doses diminishing over time in these provinces. ${ }^{39}$

In Table A6, we also present results from two alternative specifications of equation (2): using log weekly deaths and log average weekly hospitalizations as information, in columns (1) and (2), and using a binary (instead of weekly-averaged) policy variable $P_{t}$. The results are very similar to our baseline findings in Table 2 and confirm the positive and large estimated effect of mandate announcements on first dose vaccine uptake. ${ }^{40}$

\section{Counterfactual analysis}

We use our estimates of the mandate effect on vaccine uptake from Table 2 to compute the total increase in new vaccinations for each province and for France, Italy and Germany, relative to in the counterfactual scenario of absence of mandate. Calling $\hat{t}$ the mandate announcement date, we compute the counterfactual log weekly doses per 100,000 people, $\tilde{V}_{t}^{t s}$ iteratively as

$$
\begin{gathered}
\tilde{V}_{t}^{t s}=V_{t}, \text { for all } t<\hat{t} \text { and } \\
\tilde{V}_{t}^{t s}=V_{t}-\hat{\pi} P_{t}-\hat{\tau}_{2} T_{t}^{a}+\hat{\lambda}_{1}\left(\tilde{V}_{t-7}^{t s}-V_{t-7}\right)+\hat{\lambda}_{2}\left(\tilde{V}_{t-14}^{t s}-V_{t-14}\right), \text { for all } t \geq \hat{t}
\end{gathered}
$$

\footnotetext{
${ }^{39}$ We note that with hospitalizations replacing cases as control variable (see column (2) of Table A6), $\hat{\tau}_{2}$ is negative, albeit sometimes without statistical significance, for all provinces but Manitoba and Nova Scotia. Estimates for the latter two provinces show very negative $\hat{\tau}_{1}$, possibly due to the abrupt decrease in vaccinations about four weeks before their mandate announcements (see Fig. B4). Thus, we cannot rule out that a negative change in trend may be quite general for Canadian provinces.

${ }^{40}$ The policy effect estimates are positive but not statistically significantly different from zero in one specification in column (1) and 3 specifications in column (3) of Table A6, out of 26 total specifications.
} 
where $\hat{\pi}$ is the coefficient estimate of the mandate announcement variable $P_{t}$ from column (1) of Table 2, $\hat{\tau}_{2}$ is the estimate of the interaction time trend $T_{t}^{a}$ from column (2) of Table 2 , and where the terms multiplied by the estimates $\hat{\lambda}_{1}$ and $\hat{\lambda}_{2}$ account for the the lagged terms $V_{t-7}$ and $V_{t-14}$ in equation (2). The policy effect estimate $\hat{\pi}$, as well as $\hat{\tau}_{2}, \hat{\lambda}_{1}$ and $\hat{\lambda}_{2}$ are specific for each respective country or province.

The counterfactual simulations assume that all explanatory variables except the mandate announcement (e.g., deaths or time fixed effects) remain fixed at their observed values, and that the estimated model parameters remain stable. These assumptions are more plausible over relatively short periods and hence the simulations should be interpreted primarily as an illustration of the estimated impact of the proof of vaccination mandates on vaccine uptake rather than policy guidance.

\subsection{Canadian provinces}

We next use the time-series estimates in Table 2 to compute counterfactual weekly doses, $\tilde{V}_{t}^{t s}$, as defined in (3), and counterfactual total first doses for each province. The results are displayed in Fig. 4. The left vertical axis displays total first doses in millions. The right axis displays the total doses in terms of the percentage of eligible people (age 12 and above; see Table C3). The number next to the province name is the estimated percentage-point (pp) increase in first doses relative to the no-mandate counterfactual, as of October 31, 2021. In Fig. B9 we also display these results in terms of actual vs. counterfactual weekly doses. In Table A7 we report the gains in thousands of doses, along with estimated gains from alternative specifications.

Fig. 4 shows a relatively quick divergence and sizable gap between the observed and counterfactual cumulative first-dose numbers. The largest absolute gains in new vaccinations (left axis of Fig. 4 and column (1) in Table A7) are naturally in the four largest provinces (Ontario, Quebec, Alberta and British Columbia). As a proportion of the eligible population (right axis), however, we estimate the largest mandate increases in vaccine uptake to be in Saskatchewan (5 p.p., CI 4.0-5.6) and New Brunswick (5 p.p., 3.9-5.8), followed by Alberta (4.2 p.p., 3.2-4.9) and Nova Scotia (4.2 p.p., 3.6-4.7), see Fig. 5. These large gains in new first-dose vaccinations occur within 6 to 10 weeks of the mandate announcement for most provinces (13 for Quebec) and are on top of a very high base vaccination rates (above $80 \%$ of all eligible, on average), see Table C3. For example, Saskatchewan's 5 p.p. estimated gain amounts to about one quarter of all remaining unvaccinated eligible people in the province as of the mandate announcement date (Sep. 16, 2021). 
Figure 4: Canadian provinces - observed vs. no-mandate counterfactual first doses as of October 31, 2021 (time-series estimates)
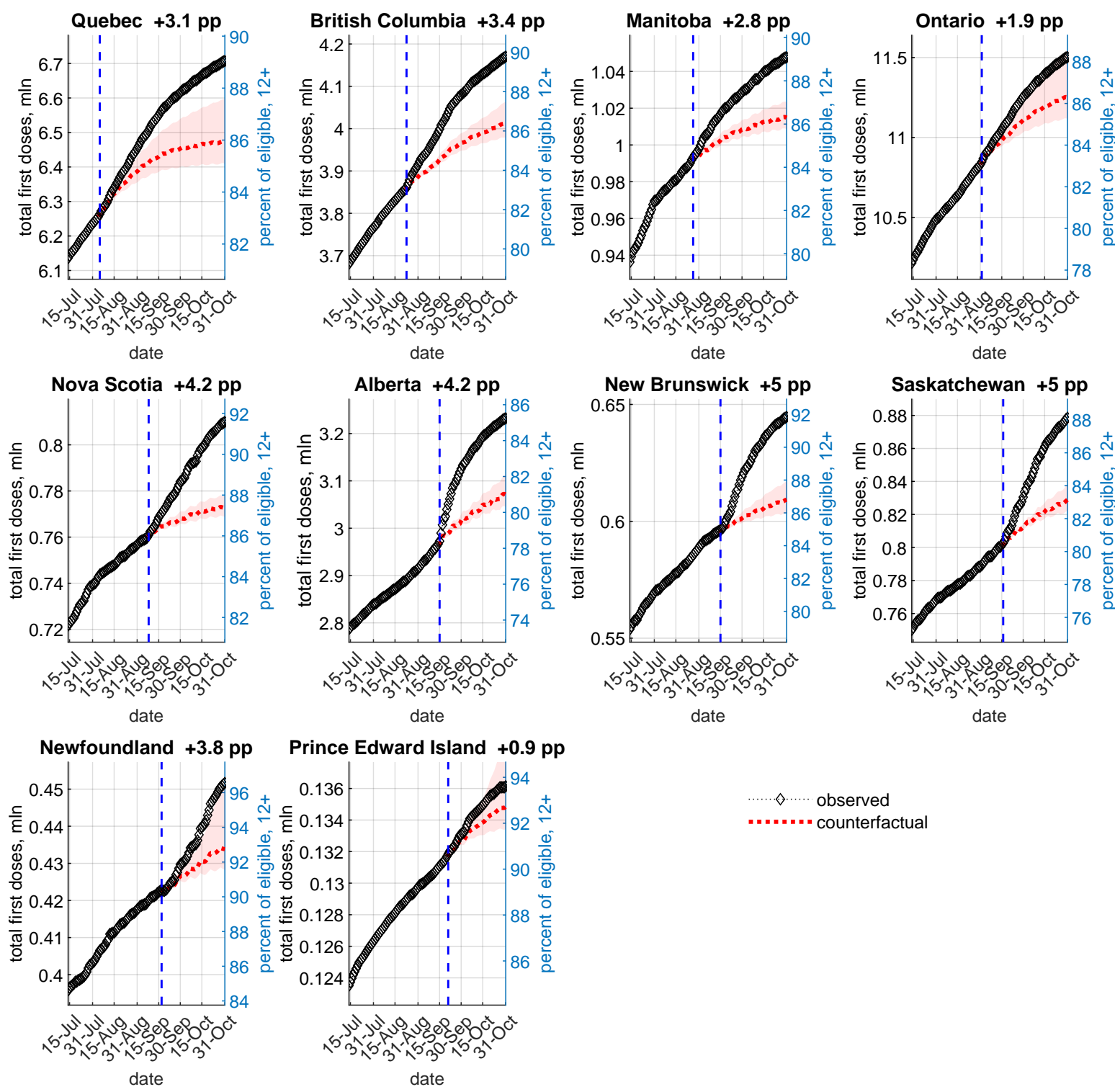

Prince Edward Island $+0.9 \mathrm{pp}$
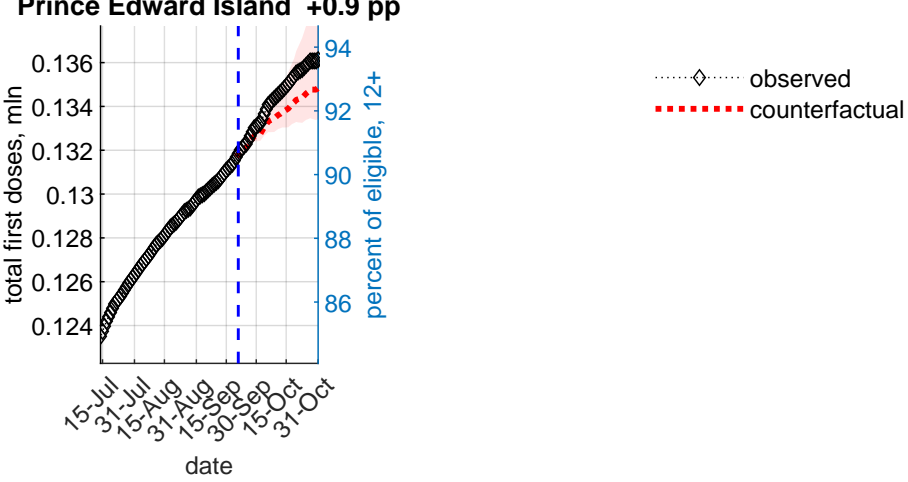

Notes: The figure plots the observed (black diamonds) and mean counterfactual (dotted red line) cumulative first doses for each province by date. The counterfactuals are computed using the estimates in Table 2. The shaded areas denote 5-95 percentile confidence bands computed computed using 1000 draws from the estimated asymptotic joint distribution of the parameters in (3). The vertical dashed line denotes the mandate announcement date. The number next to each province name indicates the mean estimated percentage point increase in first doses relative to the no-mandate counterfactual, as of October 31, 2021.

We do not find evidence of net intertemporal substitution (decrease in the cumulative first-dose gains due to pulling vaccinations forward in time) as of October 31, 2021, except in PEI. However, the strongly negative $\tau_{2}$ estimates in Table 2 and the trends in Fig. B9 
indicate that Alberta, New Brunswick and Saskatchewan are projected to exhibit net intertemporal substitution after the end of October 2021. That said, given the flattening of the counterfactual curves on Fig. 4, the cumulative gains are likely to remain significant.

In Fig. B10 we also plot a counterfactual computed using the DID estimate for Canada. ${ }^{41}$ We estimate that, as of Sep. 14, 2021, the sample end date in Table 1, the proof-of-vaccination mandates in the five Canadian provinces that announced mandates by that date have led to 287,000 additional first doses (CI 239,000-333,000) or a vaccination rate increase of 0.9 p.p. (0.7-1.0) for the eligible population ${ }^{42}$, relative to the no-mandate counterfactual.

Figure 5: Counterfactuals - percentage-point increase in vaccine uptake

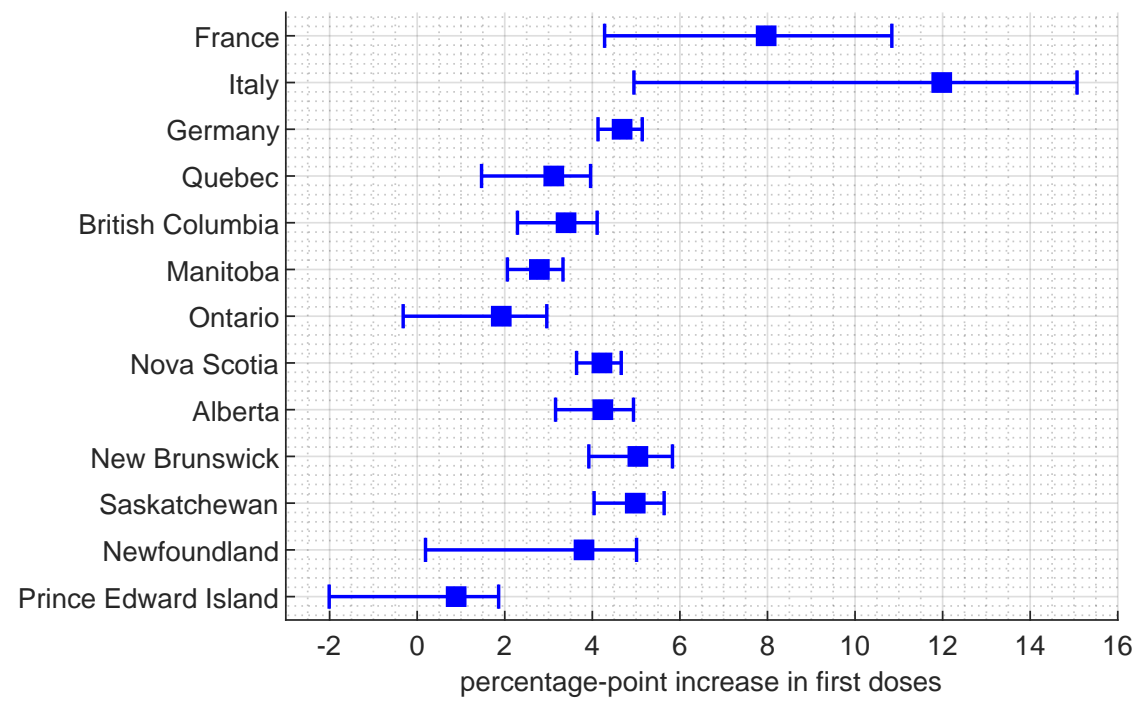

Notes: The Figure plots the total estimated percentage-point increase (mean and 90\% confidence interval) in the first dose vaccination rate after mandate announcement, as of October 31, 2021.

\subsection{Countries}

We also use the time-series estimates in Table 2 to estimate the gains in vaccine uptake for France, Italy and Germany, relative to the counterfactual assuming the absence of a proof of vaccination mandate. The results are displayed in Fig. 5, Fig. 6 and Table A7. The estimated increases in first-dose uptake after the mandate announcements are large in all three countries: 8 p.p. (4.3-10.8) or $4.59 \mathrm{mln}$ (2.47-6.25) doses in France, 12 p.p. (5.0-15.1) or $6.48 \mathrm{mln}(2.67-8.14)$ additional first doses in Italy, and 4.7 p.p. (4.1-5.1) or $3.47 \mathrm{mln}$

\footnotetext{
${ }^{41}$ We compute the counterfactual mean as $\tilde{V}_{i t}^{d i d}=V_{i t}-\hat{\alpha} P_{i t}$ where $\hat{\alpha}$ is the DID estimate on the policy variable $P_{i t}, 0.506$ in Table 1 , column (2).

${ }^{42}$ This number equals approximately $4.4 \%$ of all unvaccinated eligible people of age 12 or older at the time of the first proof-of-vaccination mandate announcement in Canada (August 5, 2021 in Quebec).
} 
medRxiv preprint doi: https://doi.org/10.1101/2021.10.21.21265355; this version posted January 13, 2022. The copyright holder for this preprint (which was not certified by peer review) is the author/funder, who has granted medRxiv a license to display the preprint in perpetuity.

All rights reserved. No reuse allowed without permission.

(3.06-3.81) doses in Germany. The larger percentage-point increase in Italy could be partly attributed to the complementary vaccination requirements for inter-regional travel and for employment introduced in September and October.

Figure 6: Countries - observed vs. no-mandate counterfactual first doses
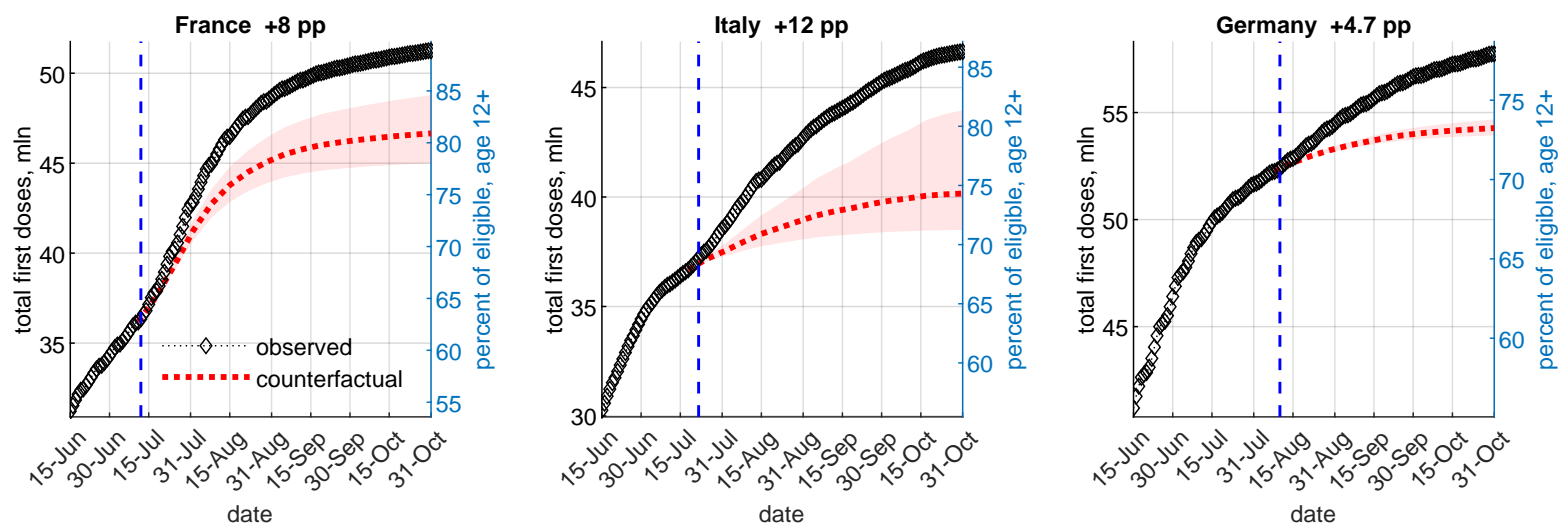

Notes: The figure plots the observed (black diamonds) and mean counterfactual (dotted red line) cumulative first doses for each country by date. The counterfactuals are computed using the estimates from Table 2. The shaded areas denote 5-95 percentile confidence bands computed using 1000 draws from the estimated asymptotic joint distribution of the parameters in (3). The vertical dashed line denotes the mandate announcement date. The number next to each country name indicates the mean estimated percentage point increase in first doses relative to the no-mandate counterfactual, as of October 31, 2021.

\section{Discussion and conclusions}

We evaluate the impact of government-mandated proof of vaccination requirements on COVID-19 vaccine uptake. Using difference-in-differences analysis and the variation of timing of mandate announcements across Canadian provinces, we estimate a statistically significant and large (66\% on average) increase in weekly first-dose uptake in Canada over the first weeks after the mandate announcement, relative to in absence of mandate. We obtain similar results from time-series analysis for each Canadian province and for France, Italy and Germany - a sizable increase in new first-dose vaccinations and lasting cumulative gains after a mandate announcement, relative to the pre-announcement trend.

The estimated mandate effect varies across the Canadian provinces, with those exhibiting a larger initial gain tending to drop back toward the baseline pace of vaccination more quickly. Using simulations based on our time-series results, we estimate that, as of October 31, 2021, all ten provinces and all three countries achieved large net increases in the firstdose vaccination rate relative to the hypothetical scenario of absence of proof of vaccination mandate: 2.9 p.p. (1.3-3.8) of the eligible population in total for Canada, 8 p.p. (4.3-10.8) 
for France, 12 p.p. (5.0-15.1) for Italy and 4.7 p.p. (4.1-5.1) for Germany. These estimates may include effects from complementary measures (e.g., vaccination requirements for health workers or for inter-regional travel, etc.) adopted after the original proof of vaccination mandates, particularly in the European countries.

In terms of external validity, in June 2020, Lazarus et al. (2021) conducted a survey on vaccine hesitancy across 19 countries comprising around $55 \%$ of the world population. ${ }^{43}$ Canada, Italy and Germany placed around the middle in the self-reported vaccine hesitancy rate $(29 \%$ to $31 \%$ ), while France had a higher hesitancy rate (41\%). In this regard, our results on the large impact of proof of vaccination mandates on first-dose uptake in these four countries can be useful to public health authorities in other places looking for an effective strategy to increase vaccine uptake.

Our objective is not to engage in normative or ethical debates related to vaccination mandates (e.g., Gostin, 2021), but to provide a benchmark range of estimates for their effectiveness in terms of new first dose uptake, which can be compared to other approaches such as monetary incentives or behavioural nudges.

Monetary incentives for vaccination have been criticized by many for the 'optics' of putting a (low) dollar value on being vaccinated, ${ }^{44}$ because of the perceived unfairness in rewarding people who delayed their vaccination, or, if payments are unavailable to those that were vaccinated earlier, because of potential moral hazard problems (e.g., expecting future payments). Related to this, Chang et al. (2021) find that financial incentives may even have the perverse effect of validating vaccine concerns among unvaccinated individuals aged 40 or above and those that supported Donald Trump in the 2020 U.S. presidential election (see also Hsieh, 2021). Others have argued that, given the already high vaccination rates in developed countries, behavioural nudges may not be very effective (Thaler, 2021), which is consistent with the findings of Chang et al. (2021) and Campos-Mercade et al. (2021).

Naturally, a full cost-benefit analysis of proof of vaccination mandates is beyond the scope of this paper. In particular, the costs of imposing and enforcing the mandates - economic, political, or personal - are very hard to estimate, as is the social value of vaccinating an additional person. ${ }^{45}$ Our results are a first step toward quantifying the benefits of proof of vaccination requirements.

\footnotetext{
${ }^{43}$ The participants were asked: "If a COVID-19 vaccine is proven safe and effective and is available, will you take it?"

${ }^{44}$ For example, in July 2021 U.S. President Joseph Biden advocated that state and local governments pay $\$ 100$ to anyone willing to receive a first dose, however, the public health value of vaccination is likely much higher (see Castillo et al., 2021).

${ }^{45}$ One component of the social value of vaccination is avoided healthcare costs. Barber and West (2021) estimate that the Ohio vaccine lottery program saved the state USD 66 million in intensive care unit costs.
} 
medRxiv preprint doi: https://doi.org/10.1101/2021.10.21.21265355; this version posted January 13, 2022. The copyright holder for this preprint (which was not certified by peer review) is the author/funder, who has granted medRxiv a license to display the preprint in perpetuity.

All rights reserved. No reuse allowed without permission.

\section{References}

[1] Alsan, M. and S. Eichmeyer (2021), "Experimental Evidence on the Effectiveness of Non-Experts for Improving Vaccine Demand", NBER Working Paper No. 28593.

[2] Andrews, N., E. Tessier, J. Stowe, C. Gower, F. Kirsebom, R. Simmons, E. Gallagher, M. Chand, K. Brown, S. Ladhani, M. Ramsay and J. Bernal (2021), "Vaccine effectiveness and duration of protection of Comirnaty, Vaxzevria and Spikevax against mild and severe COVID-19 in the UK", medRxiv preprint.

[3] Athey, S. and G. Imbens (2018), "Design-based Analysis in Difference-In-Differences Settings with Staggered Adoption", NBER Working Paper No. 24963.

[4] Barber, A. and J. West (2021), "Conditional Cash Lotteries Increase COVID-19 Vaccination Rates", working paper, UC Santa Cruz.

[5] Brehm, M., P. Brehm and M. Saavedra (2021), "The Ohio Vaccine Lottery and Starting Vaccination Rates", working paper, Oberlin College.

[6] Campos-Mercade, P., A. Meier, F. Schneider, S. Meier, D. Pope, and E. Wengström (2021), "Monetary incentives increase COVID-19 vaccinations", Science eabm0475.

[7] Callaway, B. and P. Sant'Anna (2021), "Difference-in-Differences with Multiple Time Periods." Journal of Econometrics Forthcoming.

[8] Cameron, A., J. Gelbach, and D. Miller (2008), "Bootstrap-based improvements for inference with clustered errors", Review of Economics and Statistics 90: 414-427.

[9] Castillo, J., A. Ahuja, S. Athey, A. Baker, E. Budish, T. Chipty, R. Glennerster, S. Kominers, M. Kremer, G. Larson, J. Lee, C. Prendergast, C. Snyder, A. Tabarrok, B. Tan and W. Wiecek (2021), "Market design to accelerate COVID-19 vaccine supply", Science 371: 1107-1109.

[10] Chang, T., M. Jacobson, M. Shah, R. Pramanik, and S. Shah (2021), "Financial Incentives and Other Nudges Do Not Increase COVID-19 Vaccinations among the Vaccine Hesitant", NBER Working Paper 29403.

[11] Chernozhukov, V., H. Kasahara, and P. Schrimpf (2021), "Causal Impact of Masks, Policies, Behavior on Early COVID-19 Pandemic in the U.S.", Journal of Econometrics 220(1): 23-62.

[12] Chow, G. (1960), "Tests of equality between sets of coefficients in two linear regressions", Econometrica 591-605.

[13] de Chaisemartin, C. and X. D'Haultfouille (2020), "Two-Way Fixed Effects Estimators with Heterogeneous Treatment Effects", American Economic Review 110(9): 2964-2996.

[14] Dai, H., S. Saccardo, M. Han, L. Roh, N. Raja, S. Vangala, H. Modi, S. Pandya, M. Sloyan, and D. Croymans (2021), "Behavioural nudges increase COVID-19 vaccinations", Nature 597: 404-409. 
[15] Fisher, R. (1935), The Design of Experiments, Oliver and Boyd, Edinburgh.

[16] Giles, D. and M. Scott (1992), "Some consequences of using the Chow test in the context of autocorrelated disturbances", Economics Letters 38(2): 145-150.

[17] Goodman-Bacon, A. (2021), "Difference-in-Differences with Variation in Treatment Timing", Journal of Econometrics Forthcoming.

[18] Gostin L. (2021) "COVID-19 Vaccine Mandates - A Wider Freedom", JAMA Health Forum 2(10):e213852.

[19] Grannis, S., E. Rowley, T. Ong, E. Stenehjem, N. Klein, M. DeSilva, A. Naleway, K. Natarajan and M. Thompson (2021), "Interim Estimates of COVID-19 Vaccine Effectiveness against COVID-19-Associated Emergency Department or Urgent Care Clinic Encounters and Hospitalizations Among Adults During SARS-CoV-2 B.1.617.2 (Delta) Variant Predominance - Nine States, June-August 2021", Morbidity and Mortality Weekly Report 70(37): 1291-1293.

[20] Gupta, S., J. Cantor, K. Simon, A. Bento, C. Wing and C. Whaley (2021), "Vaccinations Against COVID-19 May Have Averted Up To 140,000 Deaths In The United States", Health Affairs 40(9).

[21] Hsieh, P. (2021), "Perks and incentives for COVID-19 Vaccination May Backfire", Forbes, May 28, 2021.

[22] Karaivanov, A., S. Lu, H. Shigeoka, C. Chen and S. Pamplona (2021), "Face Masks, Public Policies and Slowing the Spread of COVID-19: Evidence from Canada", Journal of Health Economics 78, 102475.

[23] Klüver, H., F. Hartmann, M. Humphreys, F. Geissler and J. Giesecke (2021), "Incentives can spur COVID-19 vaccination uptake", Proceedings of the National Academy of Sciences 118(36).

[24] Lazarus, J., S. Ratzan, A. Palayew, L. Gostin, H. Larson, K. Rabin, S. Kimball and A. El-Mohandes (2021), "A global survey of potential acceptance of a COVID-19 vaccine", Nature Medicine 27: 225-228.

[25] Linden, A. (2017), "Conducting interrupted time-series analysis for single- and multiple-group comparisons", The Stata Journal 15(2): 480-500.

[26] Mills, M. and T. Rüttenauer (2021), "The effect of mandatory COVID-19 certificates on vaccine uptake: synthetic-control modelling of six countries", Lancet Public Health published online Dec. 13, 2021, https://doi.org/10.1016/ S2468-2667(21)00273-5.

[27] Newey, W., and K. West (1987), "A Simple, Positive Semi-definite, Heteroskedasticity and Autocorrelation Consistent Covariance Matrix", Econometrica 55(3): 703-708.

[28] Roodman D, M. Nielsen, J. MacKinnon and M. Webb (2019), "Fast and wild: Bootstrap inference in Stata using boottest", The Stata Journal 19(1):4-60. 
medRxiv preprint doi: https://doi.org/10.1101/2021.10.21.21265355; this version posted January 13, 2022. The copyright holder for this preprint (which was not certified by peer review) is the author/funder, who has granted medRxiv a license to display the preprint in perpetuity.

All rights reserved. No reuse allowed without permission.

[29] Scobie, H., A. Johnson, A. Suthar, R. Severson, N. Alden, S. Balter, D. Bertolino, D. Blythe, S. Brady, B. Cadwell, I. Cheng, S. Davidson, J. Delgadillo, K. Devinney, J. Duchin, M. Duwell, R. Fisher, A. Fleischauer, A. Grant, J. Griffin, M. Haddix, J. Hand, M. Hanson, E. Hawkins, R. Herlihy, L. Hicks, C. Holtzman, M. Hoskins, J. Hyun, R. Kaur, M. Kay, H. Kidrowski, C. Kum, K. Komatsu, K. Kugeler, M. Lewis, B.C. Lyons, S. Lyons, R. Lynfield, K. McCaffrey, C. McMullen, L. Milroy, S. Meyer, L. Nolen, M. Patel, S. Pogosjans, H. Reese, A. Saupe, J. Sell, T. Sokol, D. Sosin, E. Stanislawski, K. Stevens, H. Vest, K. White, E. Wilson, A. MacNeil, M. Ritchey and B. Silk (2021), "Monitoring Incidence of COVID-19 Cases, Hospitalizations, and Deaths, by Vaccination Status - 13 U.S. Jurisdictions, April 4-July 17, 2021", CDC Morbidity and Mortality Weekly Report 70(37): 1284-1290.

[30] Sehgal, K. (2021), "Impact of Vax-a-Million lottery on COVID-19 vaccination rates in Ohio", The American Journal of Medicine Forthcoming.

[31] Sun, B. and S. Abraham (2021), "Estimating dynamic treatment effects in event studies with heterogeneous treatment effects." Journal of Econometrics Forthcoming.

[32] Schwert, G. (1989), "Tests for unit roots: A Monte Carlo investigation." Journal of Business and Economic Statistics, Vol. 7, No. 2.

[33] Thaler, R. (2021), "More than nudges are needed to end the pandemic", The New York Times, August 5, 2021.

[34] Walkey, A., A. Law, N. Bosch (2021), "Lottery-Based Incentive in Ohio and COVID-19 Vaccination Rates", JAMA 326(8): 766-767. 
medRxiv preprint doi: https://doi.org/10.1101/2021.10.21.21265355; this version posted January 13, 2022. The copyright holder for this preprint (which was not certified by peer review) is the author/funder, who has granted medRxiv a license to display the preprint in perpetuity.

All rights reserved. No reuse allowed without permission.

\section{Acknowledgements}

We thank Serena Canaan, Hiro Kasahara and Pierre Mouganie for helpful suggestions.

\section{Author contributions}

A.K., D.K., S.L. and H.S. contributed equally to the conceptualization, writing and statistical analysis.

\section{Competing interests}

All authors declare no competing financial or other interest in the presented research.

\section{Data availability}

All data sources are described in Appendix C. The data used in the study are available at: https://github.com/C19-SFU-Econ/dataV. 


\section{Appendix A. Additional Tables}

Table A1: Canadian provinces - different control groups

\begin{tabular}{|c|c|c|c|c|c|c|}
\hline \multirow{4}{*}{$\begin{array}{l}\text { end date } \\
\text { control group } \\
\text { p-values in [] }\end{array}$} & \multicolumn{6}{|c|}{ Outcome: log weekly vaccine first doses, $V_{i t}$} \\
\hline & Sep. 20 & Sep. 16 & Sep. 15 & Sep. 14 & Sep. 7 & Aug. 31 \\
\hline & $\mathrm{PE}$ & $(1)+\mathrm{NL}$ & $(2)+\mathrm{SK}$ & $(3)+\mathrm{AB}, \mathrm{NB}$ & $(4)+\mathrm{NS}$ & $(5)+\mathrm{ON}$ \\
\hline & $(1)$ & $(2)$ & $(3)$ & $(4)$ & $(5)$ & $(6)$ \\
\hline \multirow[t]{2}{*}{ week 0} & 0.372 *** & $0.364 * *$ & $0.351 * *$ & $0.359 * * *$ & $0.384 * * *$ & $0.404 * * *$ \\
\hline & {$[0.001]$} & {$[0.019]$} & {$[0.017]$} & {$[0.005]$} & {$[0.009]$} & {$[0.000]$} \\
\hline \multirow[t]{2}{*}{ week 1} & $0.561 * * *$ & $0.552 * * *$ & $0.545 * * *$ & $0.543 * * *$ & $0.620 * * *$ & $0.837^{* * *}$ \\
\hline & {$[0.001]$} & {$[0.001]$} & {$[0.001]$} & {$[0.001]$} & {$[0.002]$} & {$[0.000]$} \\
\hline \multirow[t]{2}{*}{ week 2} & $0.442 * *$ & $0.469 * *$ & $0.477 * *$ & $0.498 * * *$ & $0.687 * * *$ & $0.767 * * *$ \\
\hline & [0.029] & {$[0.025]$} & {$[0.019]$} & {$[0.010]$} & {$[0.000]$} & {$[0.000]$} \\
\hline \multirow[t]{2}{*}{ week 3} & $0.540 * * *$ & $0.705 * * *$ & $0.695 * * *$ & $0.705 * * *$ & $0.739 * * *$ & $0.712 * * *$ \\
\hline & {$[0.006]$} & {$[0.002]$} & {$[0.001]$} & {$[0.001]$} & {$[0.002]$} & {$[0.002]$} \\
\hline \multirow[t]{2}{*}{ week 4} & $0.690 * *$ & $0.712 * *$ & $0.712 * *$ & $0.713 * * *$ & $0.710 * *$ & \\
\hline & {$[0.025]$} & {$[0.018]$} & {$[0.018]$} & [0.018] & {$[0.026]$} & \\
\hline \multirow[t]{2}{*}{ week 5} & $0.650 *$ & $0.651 *$ & $0.642 *$ & $0.651 *$ & & \\
\hline & {$[0.059]$} & {$[0.059]$} & {$[0.060]$} & {$[0.056]$} & & \\
\hline \multirow[t]{2}{*}{ week $6+$} & $0.492 *$ & $0.651 *$ & & & & \\
\hline & {$[0.089]$} & {$[0.060]$} & & & & \\
\hline R-squared & 0.811 & 0.818 & 0.820 & 0.821 & 0.829 & 0.839 \\
\hline sample size, $\mathrm{N}$ & 980 & 940 & 930 & 920 & 850 & 780 \\
\hline province fixed effects & $\mathrm{X}$ & $\mathrm{X}$ & $\mathrm{X}$ & $\mathrm{X}$ & $\mathrm{X}$ & $\mathrm{X}$ \\
\hline date fixed effects & $\mathrm{X}$ & $\mathrm{X}$ & $\mathrm{X}$ & $\mathrm{X}$ & $\mathrm{X}$ & $\mathrm{X}$ \\
\hline cases and deaths & $\mathrm{X}$ & $\mathrm{X}$ & $\mathrm{X}$ & $\mathrm{X}$ & $\mathrm{X}$ & $\mathrm{X}$ \\
\hline
\end{tabular}

Notes: Sun and Abraham (2021) treatment effect heterogeneity robust estimates. The table reports estimates for different treatment and control (latest treated) groups of provinces which determine the sample end date. "week n", where $n=0,1,2, \ldots$, is a binary variable that takes value 1 for the days in the n-th week immediately after the announcement date (week 0 is the week starting at the announcement date) and value 0 otherwise. The cases and deaths variables are log weekly totals for dates $t-6$ to $t$. P-values from wild bootstrap (boottest) standard errors clustered by province with 4,999 repetitions are reported in the square brackets. ${ }^{*}, * *$ and ${ }^{* * *}$ denote $10 \%, 5 \%$ and $1 \%$ significance respectively. 
Table A2: Robustness

\begin{tabular}{|c|c|c|c|c|c|c|c|}
\hline \multirow[t]{2}{*}{ p-values in [ ] } & \multicolumn{5}{|c|}{ Outcome: log weekly first vaccine doses, $V_{i t}$} & \multirow[b]{2}{*}{$\begin{array}{l}\text { daily } \\
\text { outcome } \\
\quad(6)\end{array}$} & \multirow[b]{2}{*}{$\begin{array}{c}\text { level } \\
\text { outcome } \\
\quad(7)\end{array}$} \\
\hline & $\begin{array}{l}\text { baseline } \\
(1)\end{array}$ & $\begin{array}{l}\text { no cases } \\
\& \text { deaths } \\
\quad(2)\end{array}$ & $\begin{array}{l}\text { deaths \& } \\
\text { hospitaliz. } \\
\quad(3)\end{array}$ & $\begin{array}{l}\text { population } \\
\text { weighted } \\
\quad(4)\end{array}$ & $\begin{array}{c}\text { OLS } \\
\text { TWFE } \\
(5)\end{array}$ & & \\
\hline \multicolumn{8}{|c|}{ A. All post-announcement dates } \\
\hline mandate announced $P_{i t}$ & $\begin{array}{l}0.506 \text { *** } \\
{[0.001]}\end{array}$ & $\begin{array}{l}0.504^{* * *} \\
{[0.002]}\end{array}$ & $\begin{array}{l}0.507 * * * \\
{[0.000]}\end{array}$ & $\begin{array}{l}0.363 * * * \\
{[0.003]}\end{array}$ & $\begin{array}{l}0.494 * * \\
{[0.020]}\end{array}$ & $\begin{array}{l}0.513 \text { *** } \\
{[0.001]}\end{array}$ & $\begin{array}{l}481.6 * \\
{[0.052]}\end{array}$ \\
\hline R-squared & 0.820 & 0.817 & 0.821 & 0.888 & 0.812 & 0.577 & 0.662 \\
\hline \multicolumn{8}{|c|}{ B. By week after the mandate announcement } \\
\hline week 0 & $\begin{array}{l}0.359 * * * \\
{[0.005]}\end{array}$ & $\begin{array}{l}0.344 * * \\
{[0.020]}\end{array}$ & $\begin{array}{l}0.362 * * * \\
{[0.002]}\end{array}$ & $\begin{array}{l}0.229 * * \\
{[0.027]}\end{array}$ & $\begin{array}{l}0.378 * * * \\
{[0.007]}\end{array}$ & $\begin{array}{l}0.517 * * * \\
{[0.001]}\end{array}$ & $\begin{array}{l}309.9 * \\
{[0.082]}\end{array}$ \\
\hline week 1 & $\begin{array}{l}0.543 * * * \\
{[0.001]}\end{array}$ & $\begin{array}{l}0.546 * * * \\
{[0.003]}\end{array}$ & $\begin{array}{l}0.545 * * * \\
{[0.000]}\end{array}$ & $\begin{array}{l}0.328 * \\
{[0.088]}\end{array}$ & $\begin{array}{l}0.570 * * \\
{[0.018]}\end{array}$ & $\begin{array}{l}0.394 * * * \\
{[0.002]}\end{array}$ & $\begin{array}{l}505.3 * \\
{[0.056]}\end{array}$ \\
\hline week 2 & $\begin{array}{l}0.498 * * \\
{[0.010]}\end{array}$ & $\begin{array}{l}0.509 * * \\
{[0.016]}\end{array}$ & $\begin{array}{l}0.503 * * \\
{[0.010]}\end{array}$ & $\begin{array}{l}0.335 * \\
{[0.056]}\end{array}$ & $\begin{array}{l}0.520 * \\
{[0.054]}\end{array}$ & $\begin{array}{l}0.431 \text { *** } \\
{[0.000]}\end{array}$ & $\begin{array}{l}510.0 * \\
{[0.088]}\end{array}$ \\
\hline week 3 & $\begin{array}{l}0.705 * * * \\
{[0.001]}\end{array}$ & $\begin{array}{l}0.693 * * * \\
{[0.001]}\end{array}$ & $\begin{array}{l}0.693 * * * \\
{[0.000]}\end{array}$ & $\begin{array}{l}0.451 * * * \\
{[0.000]}\end{array}$ & $\begin{array}{l}0.677 * * * \\
{[0.004]}\end{array}$ & $\begin{array}{l}0.672 \text { *** } \\
{[0.001]}\end{array}$ & $\begin{array}{l}676.3 * \\
{[0.027]}\end{array}$ \\
\hline week 4 & $\begin{array}{l}0.713 * * \\
{[0.018]}\end{array}$ & $\begin{array}{l}0.723 * * \\
{[0.020]}\end{array}$ & $\begin{array}{l}0.705 * * * \\
{[0.008]}\end{array}$ & $\begin{array}{l}0.370 \\
{[0.109]}\end{array}$ & $\begin{array}{l}0.672 * * \\
{[0.022]}\end{array}$ & $\begin{array}{l}0.758 \text { *** } \\
{[0.003]}\end{array}$ & $\begin{array}{l}754.1 * \\
{[0.068]}\end{array}$ \\
\hline weeks $5+$ & $\begin{array}{l}0.651 * \\
{[0.056]}\end{array}$ & $\begin{array}{l}0.678 * * \\
{[0.041]}\end{array}$ & $\begin{array}{l}0.658 * * \\
{[0.046]}\end{array}$ & $\begin{array}{l}0.286 \\
{[0.423]}\end{array}$ & $\begin{array}{l}0.650 * \\
{[0.052]}\end{array}$ & $\begin{array}{l}0.510 * \\
{[0.060]}\end{array}$ & $\begin{array}{l}732.3 \\
{[0.119]}\end{array}$ \\
\hline R-squared & 0.821 & 0.819 & 0.823 & 0.896 & 0.816 & 0.580 & 0.663 \\
\hline sample size, $\mathrm{N}$ & 920 & 920 & 920 & 920 & 920 & 920 & 920 \\
\hline province fixed effects & $\mathrm{X}$ & $\mathrm{X}$ & $\mathrm{X}$ & $\mathrm{X}$ & $\mathrm{X}$ & $\mathrm{X}$ & $\mathrm{X}$ \\
\hline date fixed effects & $\mathrm{X}$ & $\mathrm{X}$ & $\mathrm{X}$ & $\mathrm{X}$ & $\mathrm{X}$ & $\mathrm{X}$ & $\mathrm{X}$ \\
\hline
\end{tabular}

Notes: Sun and Abraham (2021) treatment effect heterogeneity robust estimates. Sample period: June 15 to September 14, 2021 using Alberta, New Brunswick, Saskatchewan, Prince Edward Island and Newfoundland as control group (latest treated); "week $\mathrm{n}$ ", where $n=0,1,2, \ldots$, is a binary variable that takes value 1 for the days in the n-th week immediately after the announcement date (week 0 is the week starting at the announcement date) and value 0 otherwise. All specifications include $\log$ weekly cases $C_{i t}$ and $\log$ weekly deaths $D_{i t}$ as information controls unless otherwise specified. P-values from wild bootstrap (boottest) standard errors clustered by province with 4,999 repetitions are reported in the square brackets. Column (1) reproduces the baseline estimates from columns (2)-(3) of Table 1. Column (2) does not control for cases and deaths. Column (3) uses log average weekly hospitalizations and log weekly deaths as information. Column (4) reports the estimates from a weighted version of equation (1) with the provinces' populations used as weights. Column (5) displays results from estimating (1) via the standard OLS two-way fixed effects (TWFE) method. Column (6) uses log daily first doses as the outcome. Column (7) uses the level of weekly first doses per 100,000 people as the outcome. *, ** and *** denote $10 \%, 5 \%$ and $1 \%$ significance respectively. 
Table A3: Robustness - standard errors

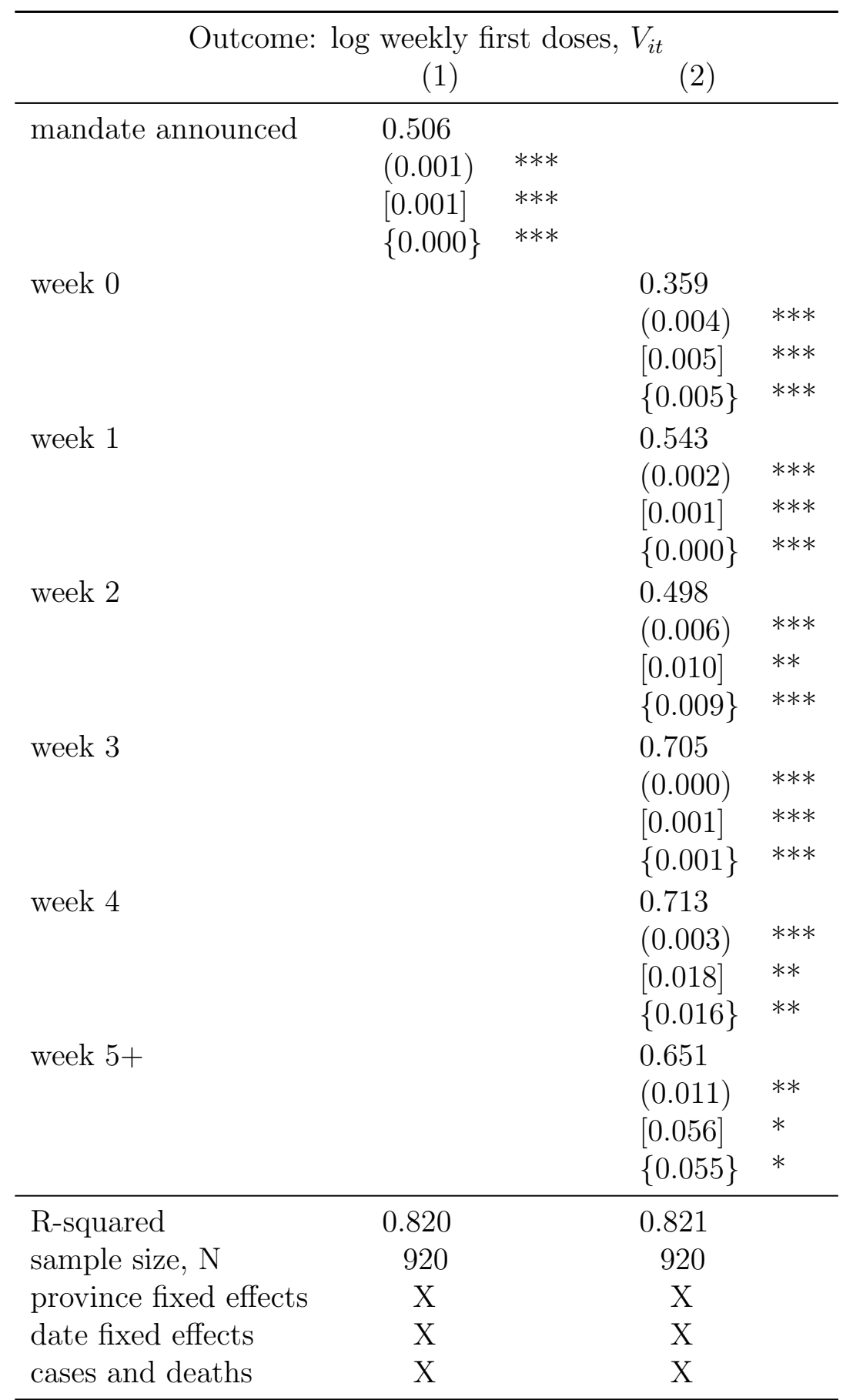

Notes: P-values from standard clustering (Stata command "cluster") by province in the ( ) parentheses; wild bootstrap (Stata command "boottest") with one-way clustering by province and 4,999 repetitions in the [ ] square brackets, and wild bootstrap with two-way clustering by province and date with 4,999 repetitions in the \{\} curly braces. "week $n$ ", where $n=0,1,2, \ldots$, is a binary variable that takes value 1 for the days in the $\mathrm{n}$-th week immediately after the announcement date (week 0 is the week starting at the announcement date) and value 0 otherwise. The cases and deaths variables are log weekly totals for dates $t-6$ to $t .{ }^{*}, * *$ and $* * *$ denote $10 \%, 5 \%$ and $1 \%$ significance respectively. 
Table A4: Second doses

\begin{tabular}{|c|c|c|c|}
\hline \multicolumn{4}{|c|}{ Outcome: log weekly vaccine second doses, $S_{i t}$} \\
\hline $\mathrm{p}$-values in [] & (1) & $(2)$ & $(3)$ \\
\hline \multirow{2}{*}{ mandate announced, $P_{i t}$} & 0.099 & 0.116 & \\
\hline & {$[0.405]$} & {$[0.298]$} & \\
\hline \multirow[t]{2}{*}{ week 0} & & & 0.041 \\
\hline & & & {$[0.630]$} \\
\hline \multirow[t]{2}{*}{ week 1} & & & 0.117 \\
\hline & & & {$[0.252]$} \\
\hline \multirow[t]{2}{*}{ week 2} & & & 0.145 \\
\hline & & & {$[0.195]$} \\
\hline \multirow[t]{2}{*}{ week 3} & & & 0.201 \\
\hline & & & {$[0.176]$} \\
\hline \multirow[t]{2}{*}{ week 4} & & & 0.177 \\
\hline & & & {$[0.243]$} \\
\hline \multirow[t]{2}{*}{ week $5+$} & & & 0.185 \\
\hline & & & {$[0.120]$} \\
\hline R-squared & 0.848 & 0.853 & 0.854 \\
\hline sample size, $\mathrm{N}$ & 920 & 920 & 920 \\
\hline province fixed effects & $\mathrm{X}$ & $\mathrm{X}$ & $\mathrm{X}$ \\
\hline date fixed effects & $\mathrm{X}$ & $\mathrm{X}$ & $\mathrm{X}$ \\
\hline log weekly cases and deaths & & $\mathrm{X}$ & $\mathrm{X}$ \\
\hline
\end{tabular}

Notes: Sun and Abraham (2021) treatment effect heterogeneity robust estimates. Time period: June 15 to September 14, 2021 using Alberta, New Brunswick, Saskatchewan, Prince Edward Island and

Newfoundland as control group (latest treated); "week $\mathrm{n}$ ", where $n=0,1,2, \ldots$, is a binary variable that takes value 1 for the days in the n-th week immediately after the announcement date (week 0 is the week starting at the announcement date) and value 0 otherwise. The cases and deaths variables are log weekly totals for dates $t-6$ to $t$. P-values from wild bootstrap (boottest) standard errors clustered by province with 5,000 repetitions are reported in the square brackets. *, ** and *** denote $10 \%, 5 \%$ and $1 \%$ significance respectively. 
medRxiv preprint doi: https://doi.org/10.1101/2021.10.21.21265355; this version posted January 13, 2022. The copyright holder for this preprint (which was not certified by peer review) is the author/funder, who has granted medRxiv a license to display the preprint in perpetuity.

All rights reserved. No reuse allowed without permission.

Table A5: Test for structural break at the mandate announcement date

\begin{tabular}{lcccc}
\hline \multicolumn{4}{c}{ Outcome: log weekly vaccine first doses } \\
& announcement & \multicolumn{3}{c}{$\mathrm{H}_{0}$ rejection p-value } \\
& date & $(1)$ & $(2)$ & $(3)$ \\
\hline Quebec & Aug. 5, 2021 & 0.0000 & 0.0000 & 0.0000 \\
British Columbia & Aug. 23, 2021 & 0.0000 & 0.0000 & 0.0000 \\
Manitoba & Aug. 27, 2021 & 0.0000 & 0.0000 & 0.0021 \\
Ontario & Sep. 1, 2021 & 0.0000 & 0.0000 & 0.0002 \\
Nova Scotia & Sep. 8, 2021 & 0.0000 & 0.0000 & $0.2067^{\dagger}$ \\
Alberta & Sep. 15, 2021 & 0.0000 & 0.0000 & 0.0001 \\
New Brunswick & Sep. 15, 2021 & 0.0000 & 0.0000 & 0.0423 \\
Saskatchewan & Sep. 16, 2021 & 0.0000 & 0.0000 & $0.2299^{\dagger}$ \\
Newfoundland & Sep. 17, 2021 & 0.0000 & 0.0000 & $0.2392^{\dagger}$ \\
Prince Edward Island & Sep. 21, 2021 & 0.0000 & 0.0000 & $0.9409^{\dagger}$ \\
France & Jul. 12, 2021 & 0.0000 & 0.0000 & 0.0238 \\
Italy & Jul. 22, 2021 & 0.0000 & 0.0000 & 0.0412 \\
Germany & Aug. 10, 2021 & 0.0000 & 0.0000 & 0.0005 \\
\hline first-differenced outcome & & & & $\mathrm{X}$ \\
controls: cases, deaths and time trend & & $\mathrm{X}$ & $\mathrm{X}$ \\
\hline
\end{tabular}

Notes: The table reports the test statistics for the Chow structural break test with known break point. The null hypothesis $\mathrm{H}_{0}$ is that there is no structural break at the mandate announcement date. Column (1) uses equation (2) but only including $V_{t-7}$ and $V_{t-14}$. Column (2) in addition controls for log weekly deaths, $\log$ weekly cases and the linear time trend $T_{t}$. Column (3) uses the first difference of log weekly first doses and includes deaths, cases and a time trend. We use a bandwidth of 50 days before and 35 days after the announcement date $(\mathrm{T}=86)$. ${ }^{\dagger}$ denotes that $\mathrm{H}_{0}$ cannot be rejected at the $90 \%$ confidence level. 
medRxiv preprint doi: https://doi.org/10.1101/2021.10.21.21265355; this version posted January 13, 2022. The copyright holder for this preprint (which was not certified by peer review) is the author/funder, who has granted medRxiv a license to display the preprint in perpetuity.

All rights reserved. No reuse allowed without permission.

Table A6: Time series estimates - alternative specifications

\begin{tabular}{|c|c|c|c|c|}
\hline \multirow[b]{3}{*}{$\mathrm{p}$-values in [ ] } & \multicolumn{4}{|c|}{ Outcome: log weekly vaccine first doses } \\
\hline & \multicolumn{2}{|c|}{ deaths and hospitalizations } & \multicolumn{2}{|c|}{ binary $P_{t}$} \\
\hline & $\begin{array}{r}\text { policy } \hat{\pi} \\
(1) \\
\end{array}$ & $\begin{array}{c}\text { trend change } \hat{\tau_{2}} \\
(2)\end{array}$ & $\begin{array}{c}\text { policy } \hat{\pi} \\
(3)\end{array}$ & $\begin{array}{c}\text { trend change } \hat{\tau}_{2} \\
(4)\end{array}$ \\
\hline \multicolumn{5}{|l|}{ Countries } \\
\hline France & $\begin{array}{l}0.468 * * * \\
{[0.000]}\end{array}$ & $\begin{array}{l}-0.009 * * \\
{[0.026]}\end{array}$ & $\begin{array}{l}0.040 \\
{[0.321]}\end{array}$ & $\begin{array}{l}0.004 \\
{[0.205]}\end{array}$ \\
\hline Italy & $\begin{array}{l}0.516 * * \\
{[0.035]}\end{array}$ & $\begin{array}{l}0.014 \\
{[0.132]}\end{array}$ & $\begin{array}{l}0.799 * * * \\
{[0.003]}\end{array}$ & $\begin{array}{l}-0.000 \\
{[0.967]}\end{array}$ \\
\hline Germany & $\begin{array}{l}0.385 * * * \\
{[0.000]}\end{array}$ & $\begin{array}{l}0.007 * * * \\
{[0.000]}\end{array}$ & $\begin{array}{l}0.274 * * * \\
{[0.001]}\end{array}$ & $\begin{array}{l}0.007 * * * \\
{[0.002]}\end{array}$ \\
\hline \multicolumn{5}{|l|}{ Canadian provinces } \\
\hline Quebec & $\begin{array}{l}0.389 * * * \\
{[0.000]}\end{array}$ & $\begin{array}{l}-0.003 \\
{[0.387]}\end{array}$ & $\begin{array}{l}0.016 \\
{[0.841]}\end{array}$ & $\begin{array}{l}0.018 * * \\
{[0.027]}\end{array}$ \\
\hline British Columbia & $\begin{array}{l}0.626 * * * \\
{[0.000]}\end{array}$ & $\begin{array}{l}-0.007 * * * \\
{[0.000]}\end{array}$ & $\begin{array}{l}0.566 * * * \\
{[0.000]}\end{array}$ & $\begin{array}{l}-0.003 \\
{[0.507]}\end{array}$ \\
\hline Manitoba & $\begin{array}{l}0.735 * * * \\
{[0.000]}\end{array}$ & $\begin{array}{l}0.019 * * \\
{[0.018]}\end{array}$ & $\begin{array}{l}0.586 * * * \\
{[0.002]}\end{array}$ & $\begin{array}{l}0.012 * \\
{[0.066]}\end{array}$ \\
\hline Ontario & $\begin{array}{l}0.322 * * * \\
{[0.003]}\end{array}$ & $\begin{array}{l}-0.002 \\
{[0.459]}\end{array}$ & $\begin{array}{l}0.209 * * \\
{[0.022]}\end{array}$ & $\begin{array}{l}0.002 \\
{[0.763]}\end{array}$ \\
\hline Nova Scotia & $\begin{array}{l}0.726 * * * \\
{[0.007]}\end{array}$ & $\begin{array}{l}0.002 \\
{[0.782]}\end{array}$ & $\begin{array}{l}0.470 * * * \\
{[0.003]}\end{array}$ & $\begin{array}{l}0.026 * * * \\
{[0.003]}\end{array}$ \\
\hline Alberta & $\begin{array}{l}1.401 * * * \\
{[0.000]}\end{array}$ & $\begin{array}{l}-0.028^{* * *} \\
{[0.000]}\end{array}$ & $\begin{array}{l}0.983 * * * \\
{[0.000]}\end{array}$ & $\begin{array}{l}-0.015^{* * *} \\
{[0.001]}\end{array}$ \\
\hline New Brunswick & $\begin{array}{l}1.220 * * * \\
{[0.000]}\end{array}$ & $\begin{array}{l}-0.014 * * \\
{[0.041]}\end{array}$ & $\begin{array}{l}0.723 * * * \\
{[0.006]}\end{array}$ & $\begin{array}{l}-0.007 \\
{[0.431]}\end{array}$ \\
\hline Saskatchewan & $\begin{array}{l}0.809 * * * \\
{[0.000]}\end{array}$ & $\begin{array}{l}-0.009 * \\
{[0.087]}\end{array}$ & $\begin{array}{l}0.644 * * * \\
{[0.000]}\end{array}$ & $\begin{array}{l}-0.000 \\
{[0.945]}\end{array}$ \\
\hline Newfoundland & $\begin{array}{l}0.327 \\
{[0.146]}\end{array}$ & $\begin{array}{l}-0.001 \\
{[0.944]}\end{array}$ & $\begin{array}{l}0.126 \\
{[0.534]}\end{array}$ & $\begin{array}{l}0.011 \\
{[0.431]}\end{array}$ \\
\hline Prince Edward Island & $\begin{array}{l}0.323 * \\
{[0.053]}\end{array}$ & $\begin{array}{l}-0.019 * * * \\
{[0.002]}\end{array}$ & $\begin{array}{l}0.362 * * * \\
{[0.005]}\end{array}$ & $\begin{array}{l}-0.0122^{* *} \\
{[0.047]}\end{array}$ \\
\hline
\end{tabular}

Notes: Time period - June 15 to October 31, 2021. All rows include 7-day and 14-day lags of the outcome variable. Columns (1) and (3) report the coefficient estimate $\hat{\pi}$ on the "mandate announced" policy variable $P_{t}$ in equation (2). Columns (2) and (4) report the estimate $\hat{\tau_{2}}$ on the post-announcement (interaction) time trend. Columns (1) and (2) use log weekly deaths and log average weekly hospitalizations as information; columns (3) and (4) use a binary (not weekly averaged) policy variable $P_{t}$. P-values computed using Newey-West heteroskedasticity and autocorrelation robust (HAC) standard errors with 3 lags are in the square brackets. ${ }^{*},{ }^{* *}$ and ${ }^{* * *}$ denote $10 \%, 5 \%$ and $1 \%$ significance respectively. 
medRxiv preprint doi: https://doi.org/10.1101/2021.10.21.21265355; this version posted January 13, 2022. The copyright holder for this preprint (which was not certified by peer review) is the author/funder, who has granted medRxiv a license to display the preprint in perpetuity.

All rights reserved. No reuse allowed without permission.

Table A7: Counterfactuals - increase in first doses relative to no mandate as of Oct. 31, 2021

\begin{tabular}{|c|c|c|c|c|}
\hline \multirow[t]{2}{*}{ specification: } & \multicolumn{2}{|c|}{$\begin{array}{c}\text { baseline: } \\
\text { cases and deaths }\end{array}$} & \multirow{2}{*}{$\begin{array}{c}\text { deaths and } \\
\text { hospitalizations } \\
\text { total } \\
(3)\end{array}$} & \multirow{2}{*}{$\begin{array}{r}\text { binary } P_{t} \\
\text { total } \\
(4)\end{array}$} \\
\hline & $\begin{array}{r}\text { total } \\
(1)\end{array}$ & $\begin{array}{c}90 \% \mathrm{CI} \\
(2)\end{array}$ & & \\
\hline \multicolumn{5}{|c|}{ Countries (million doses) } \\
\hline France & 4.59 & $(2.47-6.25)$ & 4.80 & 2.86 \\
\hline Italy & 6.48 & $(2.67-8.14)$ & 6.23 & 5.78 \\
\hline Germany & 3.47 & $(3.06-3.81)$ & 3.52 & 3.37 \\
\hline \multicolumn{5}{|c|}{ Canadian provinces (thousand doses) } \\
\hline Quebec & 235 & $(111-298)$ & 177 & 229 \\
\hline British Columbia & 158 & $(106-191)$ & 113 & 157 \\
\hline Manitoba & 32.8 & $(24.2-39.1)$ & 35.9 & 32.9 \\
\hline Ontario & 251 & $(-41.6-386)$ & 192 & 210 \\
\hline Nova Scotia & 37.4 & $(32.2-41.2)$ & 34.7 & 37.4 \\
\hline Alberta & 161 & $(120-187)$ & 138 & 157 \\
\hline New Brunswick & 35.4 & $(27.5-40.9)$ & 33.7 & 26.7 \\
\hline Saskatchewan & 49.7 & $(40.3-56.2)$ & 41.8 & 54.6 \\
\hline Newfoundland & 17.8 & $(8.7-23.4)$ & 13.3 & 14.3 \\
\hline Prince Edward Island & 1.3 & $(-2.9-2.7)$ & -0.1 & 1.5 \\
\hline Canada (total) & 979 & $(425-1,266)$ & 779 & 920 \\
\hline
\end{tabular}

Notes: The table displays the estimated increase in first-dose uptake, defined as the difference between total observed first-dose vaccinations and the mean estimated counterfactual first doses in the absence of vaccination mandate, as of October 31, 2021. Columns (1) and (2) use our baseline specification from Table 2 with log weekly cases and deaths as information. Columns (3) uses log weekly deaths and $\log$ average weekly hospitalizations as information. Column (4) uses a binary policy variable instead of weekly average. The numbers for Canada in the last row are sums of the provincial gains. 


\section{Appendix B. Additional Figures}

Figure B1: Share of people with at least one dose - example countries

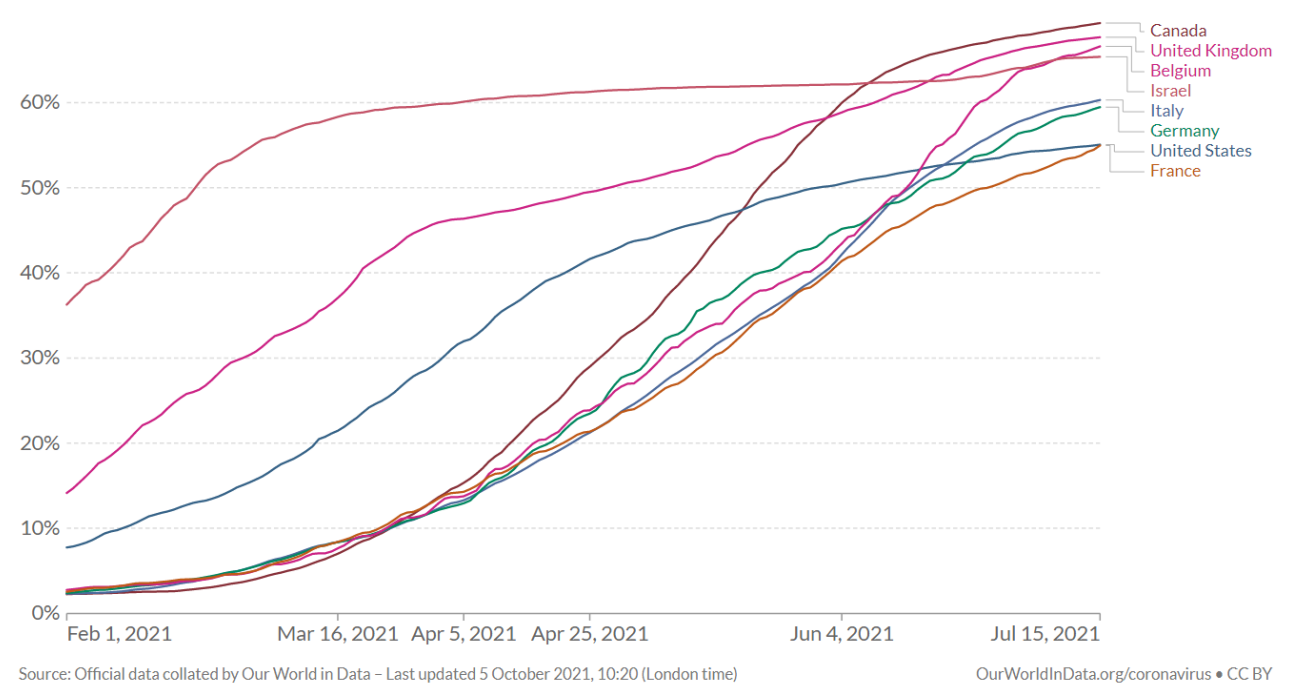

Notes: The Figure plots the share of the population who have received at least one dose of a COVID-19 vaccine in selected countries. Source: Our World in Data.

Figure B2: France - first-dose vaccination appointments

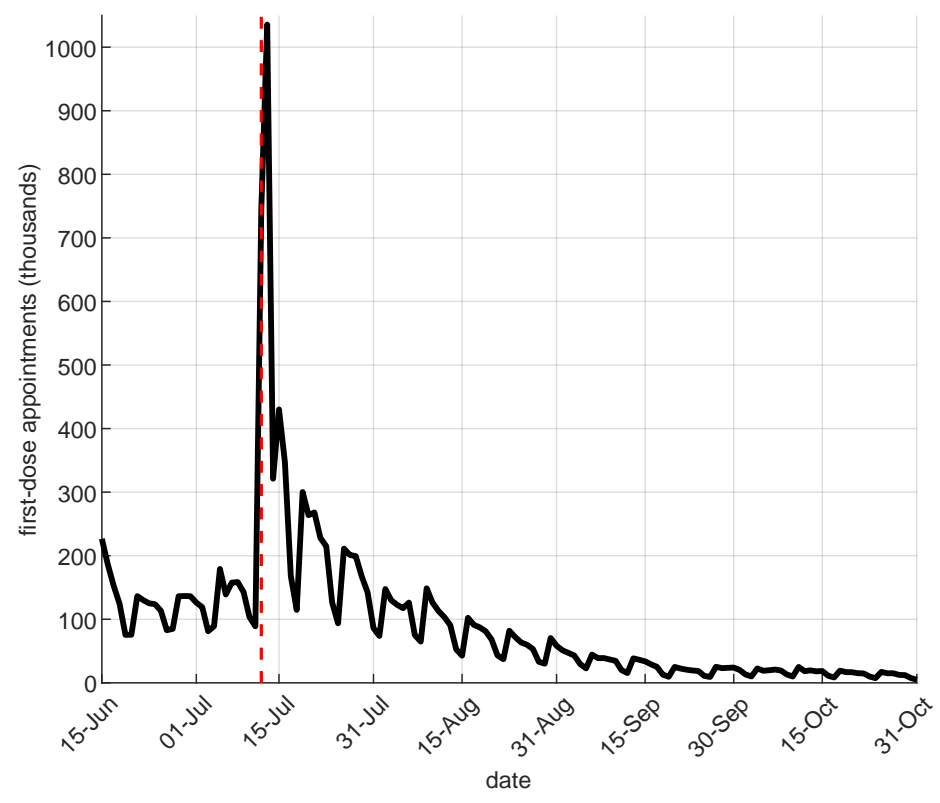

Notes: The figure plots the daily first-dose vaccination appointments by date made on Doctolib, a booking website accounting for about 2/3 of cumulative COVID-19 vaccinations in France as of Q4 2021. Source: doctolib.fr. The dashed red line denotes the mandate announcement date, July 12, 2021. 
medRxiv preprint doi: https://doi.org/10.1101/2021.10.21.21265355; this version posted January 13, 2022. The copyright holder for this preprint (which was not certified by peer review) is the author/funder, who has granted medRxiv a license to display the preprint in perpetuity.

All rights reserved. No reuse allowed without permission.

Figure B3: Canada - proof of vaccination mandates over time

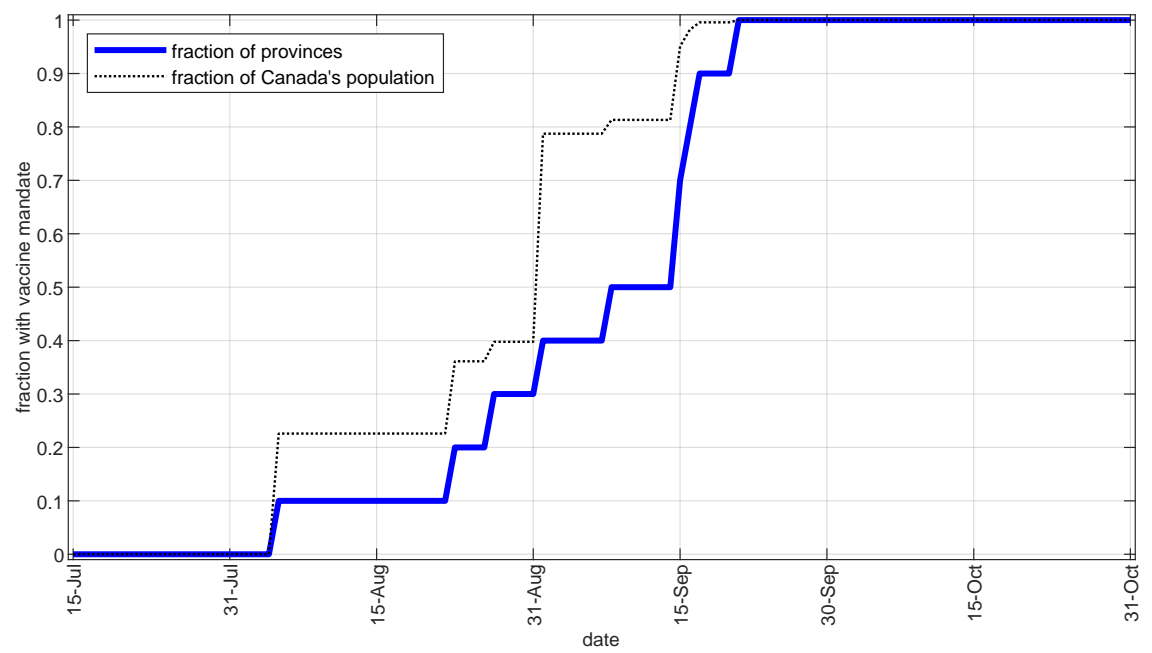

Notes: The figure plots the cumulative fraction of provinces and the cumulative fraction of Canada's population for which a proof of vaccination mandate has been announced. See Table C1 for the exact dates of mandate announcement in each province. 
Figure B4: Canadian provinces - first doses per 100,000 people
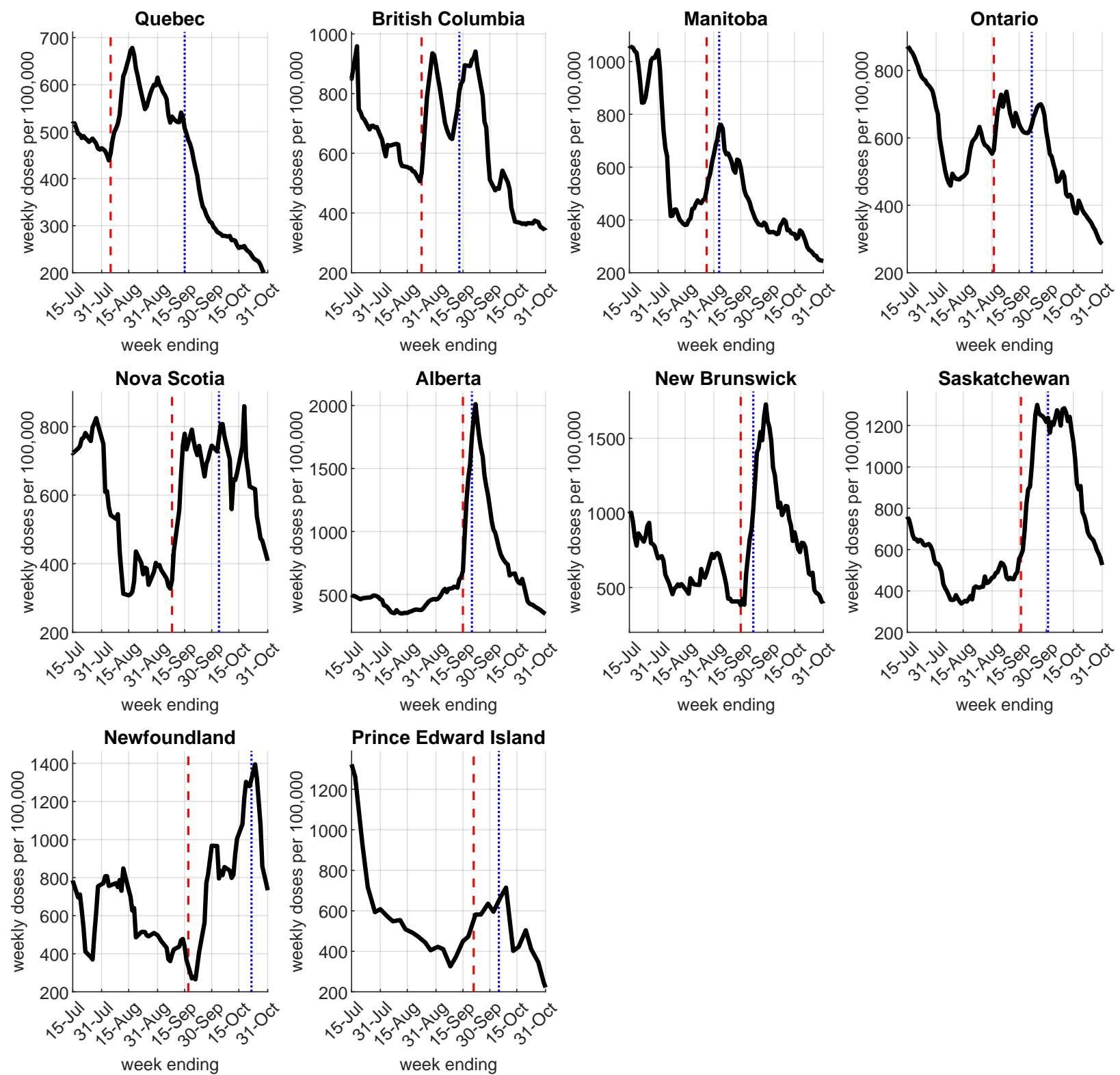

Notes: The figure plots the weekly administered COVID-19 vaccine first doses per 100,000 people for dates $t-6$ to $t$, where $t$ is the date on the horizontal axis. The dashed red lines denote the proof of vaccination mandate announcement date for each province. The dotted blue lines denote the mandate implementation (enforcement) date for each province (see Table C1). 
Figure B5: Robustness
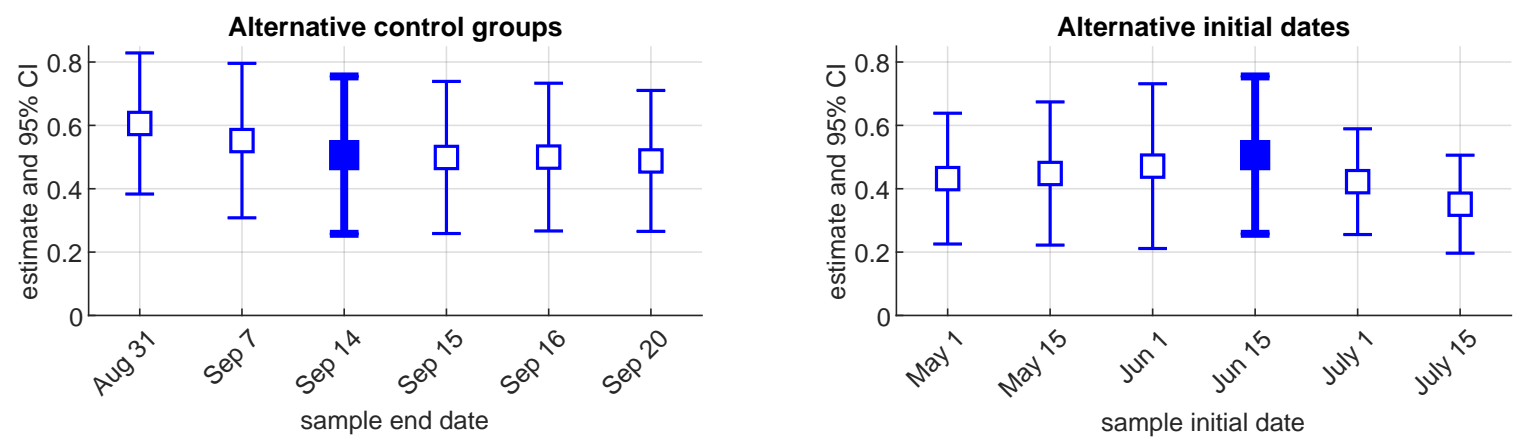

Policy lag
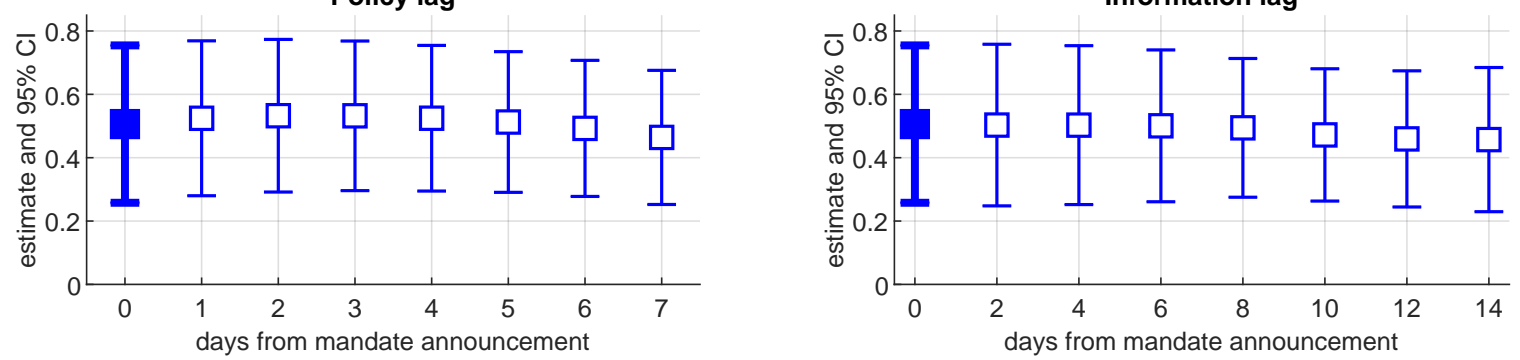

Notes: The upper left panel shows the estimates $\hat{\alpha}$ and $95 \%$ confidence intervals for the mandate announcement variable $P_{i t}$ in equation (1) with different sample end dates and corresponding control groups, including the baseline (Sep. 14, in bold). The upper right panel shows the estimates for $P_{i t}$ with different initial sample dates (May 1 to July 15, 2021), including the baseline (June 15, 2021, in bold). The lower left panel shows the estimates from a variant of equation (1) when using no lag in the policy announcement $P_{i t}$ (in bold, our baseline) and using lag of up to 7 days, i.e., $P_{i t-k}$ for $k=1,2, \ldots, 7$. The lower right panel displays the estimates from a variant of equation (1) when using no lag for the information (cases and deaths) $I_{i t}$ (in bold, our baseline) or using lag of up to 14 days, i.e., $I_{i t-k}$ for $k=2, \ldots, 14$.

Figure B6: Random assignment of announcement dates

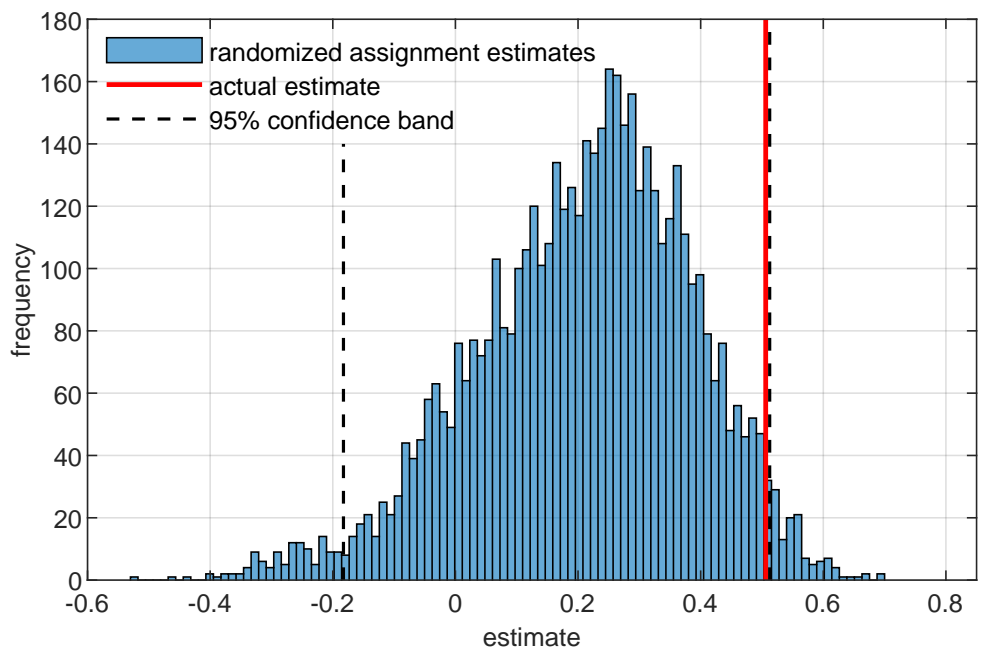

Notes: We estimate equation (1) 5,000 times using the Sun and Abraham (2021) treatment effect heterogeneity robust estimator after randomly assigning the date of mandate announcement for each province which has announced a mandate by Sep. 14. The figure plots the histogram of these placebo inference estimates, along with the 2.5-th and 97.5-th percentiles (dashed lines). The solid vertical red line corresponds to the baseline estimate from column (2) in Table 1. 
Figure B7: Canadian provinces - second doses per 100,000 people
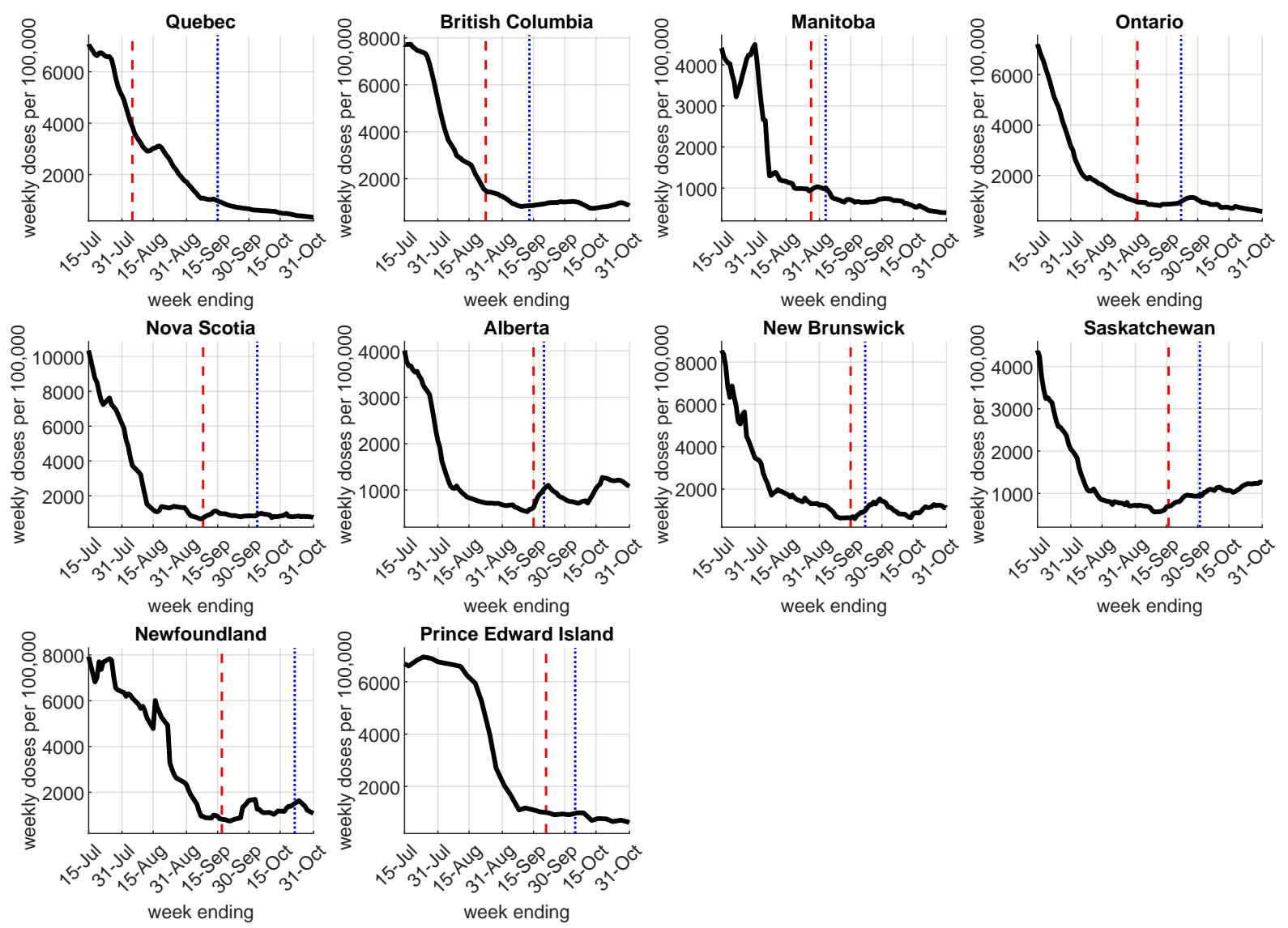

Notes: The figure plots the weekly administered COVID-19 vaccine second doses per 100,000 people for dates $t-6$ to $t$, where $t$ is the date on the horizontal axis. The dashed red lines denote the vaccination proof mandate announcement date for each province. The dotted blue lines denote the mandate implementation (enforcement) date for each province (see Table C1).

Figure B8: Time-series policy estimates - correlations
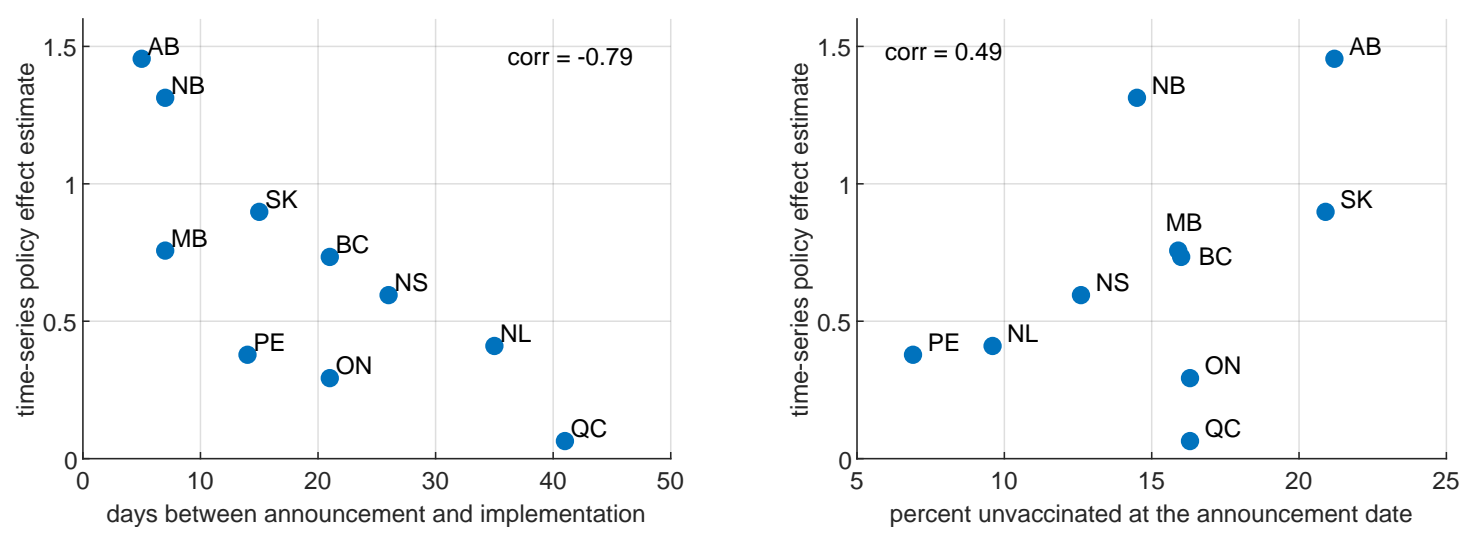

Notes: The figure plots the time-series policy estimates, $\hat{\pi}$ from Table 2 column (1) against the number of days between mandate announcement and implementation (left) and the percent remaining unvaccinated eligible people at the announcement date (right). The figure is for illustration; no causal claims are made. 
Figure B9: Canadian provinces - observed vs. no-mandate counterfactual weekly first doses as of October 31, 2021 (time-series estimates)
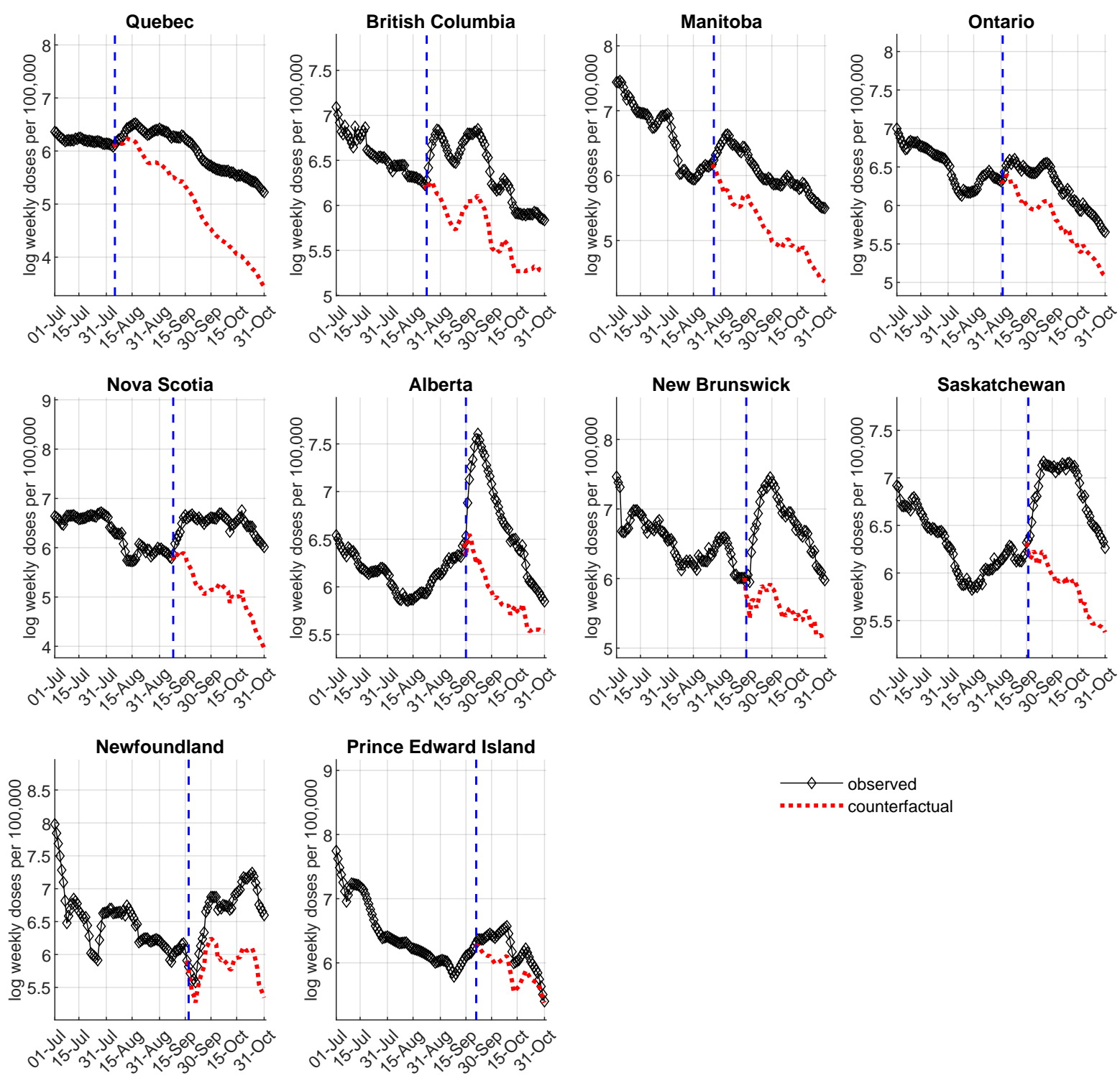

Notes: The figure plots the observed (black diamonds) and the expected no-mandate counterfactual (dashed red lines) log weekly first doses per 100,000 people. We use the estimates from Table 2 to compute the counterfactuals, as specified in (3). The dashed blue vertical lines denote the mandate announcement date for each province. 
medRxiv preprint doi: https://doi.org/10.1101/2021.10.21.21265355; this version posted January 13, 2022. The copyright holder for this preprint (which was not certified by peer review) is the author/funder, who has granted medRxiv a license to display the preprint in perpetuity. All rights reserved. No reuse allowed without permission.

Figure B10: Canada - observed vs. no-mandate counterfactual first doses as of September 14, 2021 (DID estimate)

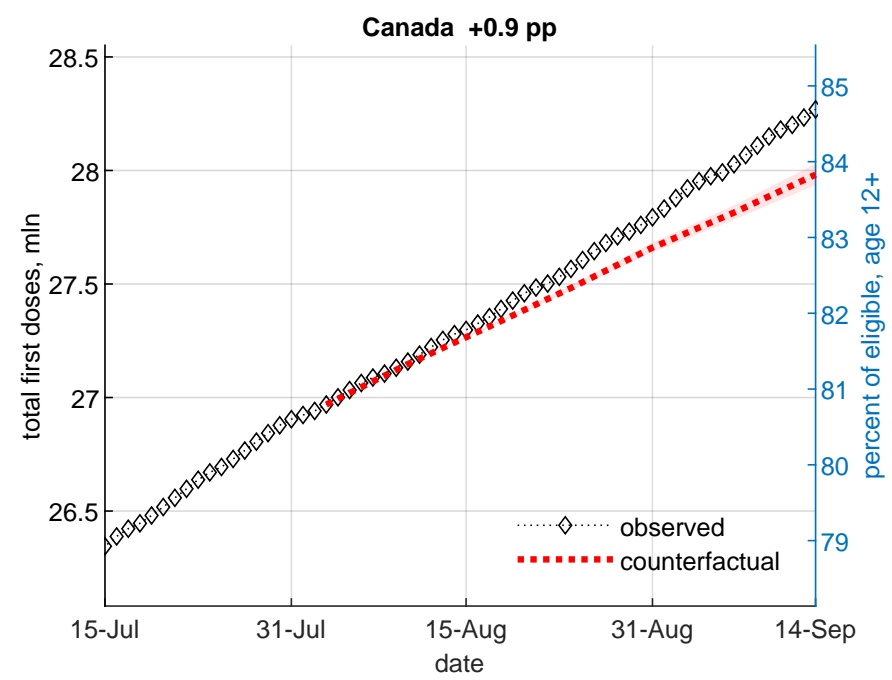

Notes: The figure plots the observed (black diamonds) and the mean no-mandate counterfactual (dotted red line) cumulative first doses (in millions) by date, with 5-95 percentile confidence bands (the shaded area). The counterfactual uses the $P_{i t}$ coefficient estimate from column (2) of Table 1 . The number in the caption indicates the percentage point increase in first doses relative to the no-mandate counterfactual as of September 14, 2021. 


\section{Appendix C. Supplementary Information}

Table C1: Proof of vaccination mandate announcement and implementation dates

\begin{tabular}{lrr}
\hline & Announcement date & Implementation date \\
\hline Canadian provinces & & \\
Quebec & August 5, 2021 & September 15, 2021 \\
British Columbia & August 23, 2021 & September 13, 2021 \\
Manitoba & August 27, 2021 & September 3, 2021 \\
Ontario & September 1, 2021 & September 22, 2021 \\
Nova Scotia & September 8, 2021 & October 4, 2021 \\
Alberta & September 15, 2021 & September 20, 2021 \\
New Brunswick & September 15, 2021 & September 22, 2021 \\
Saskatchewan & September 16, 2021 & October 1, 2021 \\
Newfoundland and Labrador ${ }^{1}$ & September 17, 2021 & October 22, 2021 \\
Prince Edward Island & September 21, 2021 & October 5, 2021 \\
Countries & & \\
France & & \\
Italy & July 12, 2021 & July 21, 2021 \\
Germany & July 22, 2021 & August 6, 2021 \\
\hline
\end{tabular}

Notes: Some jurisdictions implemented the proof of vaccination mandates in stages, e.g., in terms of the extent of vaccination required (at least one dose or full vaccination) or in terms of the scope of the mandate (e.g., only for very large events or across a wide array of settings); in these cases, we report the date on which the first stage with wide application started to be enforced. See Table C5 for more details on the mandates' scope. ${ }^{1}$ Newfoundland's mandate was announced by the provincial premier on Sep. 17, 2021, but the full details were officially unveiled on Oct. 7, 2021.

Table C2: Canada - age 12+ eligibility dates for first vaccine dose

\begin{tabular}{ll}
\hline Quebec & May 25, 2021 \\
British Columbia & May 19, 2021 \\
Manitoba & May 14, 2021 \\
Ontario & May 23, 2021 \\
Nova Scotia & May 27, 2021 \\
Alberta & May 10, 2021 \\
New Brunswick & May 26, 2021 \\
Saskatchewan & May 20, 2021 \\
Newfoundland and Labrador & May 17, 2021 \\
Prince Edward Island & May 18, 2021 \\
\hline
\end{tabular}

Notes: The table reports the first date at which any person of age 12 or higher was eligible to register and receive first dose of a COVID-19 vaccine in the respective province. 
medRxiv preprint doi: https://doi.org/10.1101/2021.10.21.21265355; this version posted January 13, 2022. The copyright holder for this preprint (which was not certified by peer review) is the author/funder, who has granted medRxiv a license to display the preprint in perpetuity.

All rights reserved. No reuse allowed without permission.

Table C3: Vaccine eligible population (age 12 or older)

\begin{tabular}{lrr}
\hline & Total eligible & $\begin{array}{r}\text { Percent unvaccinated on } \\
\text { mandate announcement date }\end{array}$ \\
\hline Quebec & $7,532,499$ & $16.3 \%$ \\
British Columbia & $4,644,795$ & $16.0 \%$ \\
Manitoba & $1,176,020$ & $15.9 \%$ \\
Ontario & $13,038,060$ & $16.3 \%$ \\
Nova Scotia & 884,351 & $12.6 \%$ \\
Alberta & $3,791,765$ & $21.2 \%$ \\
New Brunswick & 701,871 & $14.5 \%$ \\
Saskatchewan & 996,908 & $20.9 \%$ \\
Newfoundland and Labrador & 467,761 & $9.6 \%$ \\
Prince Edward Island & 145,432 & $6.9 \%$ \\
France & $57,668,019$ & $37.0 \%$ \\
Italy & $54,036,939$ & $31.2 \%$ \\
Germany & $74,100,000$ & $29.3 \%$ \\
\hline
\end{tabular}

Notes: The table reports the number of vaccine eligible people (age 12 or older) by province or country. The numbers are approximate (best estimates). Sources: Canada (link), France (link), Italy (link), Germany (link).

Table C4: Data sources

\begin{tabular}{lccc}
\hline Location & Vaccinations & Cases & Deaths \\
\hline Canadian provinces & & & \\
Alberta (AB) & link & link & link \\
British Columbia (BC) & link & link & link \\
Ontario (ON) & link & link & link \\
Quebec (QC) & link & link & link \\
Saskatchewan (SK) & link & link & link \\
Nova Scotia (NS) & link & link & link \\
Manitoba (MB) & link & link & link \\
New Brunswick (NB) & link & link & link \\
Newfoundland and Labrador (NL) & link & link & link \\
Prince Edward Island (PE) & link & link & link \\
Countries & & & \\
France, Italy, Germany & Our World In Data (OWID) \\
\hline
\end{tabular}

Notes: The data used in the paper are available at https://github.com/C19-SFU-Econ/dataV. The Canadian provincial data was last downloaded on Nov. 4, 2021. The country data was downloaded from OWID on Nov. 6, 2021. The BC and NS vaccinations data was manually collected from the official government bulletins. The NL vaccination data source is COVID-19 Canada Open Data Working Group, which archives official data from the provincial dashboards. In addition, the hospitalizations data used in the robustness analysis is from the COVID-19 Tracker database (for the Canadian provinces, retrieved Nov. 12, 2021), OWID (for France and Italy, retrieved Nov. 6, 2021), and the Robert Koch Institute (for Germany, retrieved Dec. 14, 2021). 


\section{Table C5: Proof of vaccination mandates scope}

Quebec

British

Columbia

Manitoba

Ontario

Nova Scotia

Alberta $^{1}$

\section{Canadian Provinces}

Health and social facilities (hospitals, rehabilitation, etc.); Private seniors' residences; indoor sports and physical activities; outdoor organized sports and physical activities involving frequent or prolonged contact; Outdoor events and festivals with more than 50 spectators or participants; Sporting events or shows (play, concert, musical or comedy shows etc.) in outdoor stadiums or outdoor stage; Agricultural fairs; Festivals or celebrations; Walks, marathons, cycling circuits; Golf tournaments; Immersive or walking tours; Performance venues; Stadiums and arenas; Auditoriums; Movie theatres; Indoor sport events at which the number of spectators exceeds 250 people seated in assigned seats; Bars and restaurants, including patios; Fast food restaurant dining rooms, including patios; Nightclubs; Microbreweries; Distilleries; Shopping mall food courts and food stores; Arcades, theme parks, amusement parks and centres, recreation centres, and water parks; Casinos and gambling halls, including bingo; Tourist and recreational cruises; Conventions and conferences.

Indoor ticketed sporting events with more than 50 people; Indoor concerts, theatre, dance and symphony events with more than 50 people; Licensed restaurants and cafes and restaurants and cafes that offer table service (indoor and patio dining); Liquor tasting rooms in wineries, breweries or distilleries; Pubs, bars and lounges (indoor and patio); Nightclubs, casinos and movie theatres; Gyms, exercise and dance facilities or studios; Businesses offering indoor exercise/fitness; Indoor adult group and team sports for people 22 or older; Indoor organized events with more than 50 people (e.g., weddings, funeral receptions, organized parties, conferences, trade fairs and workshops); Indoor organized group recreational classes and activities with more than 50 people; Post-secondary student housing; Spectators at indoor youth sporting events with more than 50 people.

Indoor and outdoor ticketed sporting events and concerts; Indoor theatre/dance/symphony events; Restaurants (indoor and patio dining); Nightclubs and all other licensed premises; Casinos, bingo halls and VLT lounges; Movie theatres; Fitness centres, gyms and indoor sporting and recreational facilities (excluding youth recreational sport); Organized indoor group recreational classes and activities and indoor recreational business.

Restaurants, bars and other food and drink establishments; food or drink establishments with dance facilities, including nightclubs, restoclubs, and outdoor areas of these establishments; meeting and event spaces; facilities used for sports and recreational fitness activities and personal physical fitness training, including: gyms, fitness, sporting and recreational facilities; pools; leagues, sporting events; waterparks; indoor areas of facilities where spectators watch events; casinos, bingo halls and other gaming establishments; concert venues, theatres and cinemas; bathhouses, sex clubs and strip clubs; horse racing tracks, car racing tracks and other similar venues; commercial film and TV productions where there is a studio audiences; any of the following outdoor areas that have a normal capacity of 20,000 or more people: outdoor meeting and event spaces; outdoor facilities used for sports and recreational fitness activities; outdoor concert venues, theatres and cinemas.

Full-service restaurants where patrons sit at tables to be served, both indoors and on patios; food establishments (like fast food and coffee shops) where people sit to eat and drink, both indoors and on patios (not including food courts, takeout, drive-thru or delivery); liquor licensed (drinking) establishments (like bars, wineries, distillery tasting rooms, craft taprooms and liquor manufacturers), both indoors and on patios; casinos and gaming establishments, both indoors and on patios; fitness establishments (like gyms and yoga studios) and sport and recreation facilities (like arenas, pools and large multipurpose recreation facilities); businesses and organizations offering indoor and outdoor recreation and leisure activities (like climbing facilities, dance classes, escape rooms, go-carts, indoor arcades, indoor play spaces, music lessons, pottery painting, shooting ranges and outdoor adventure); indoor and outdoor festivals, special events and arts and culture events (like theatre performances, concerts and movie theatres); indoor and outdoor sports practices, games, competitions and tournaments (participants and spectators); indoor and outdoor extracurricular school-based activities, including sportsbus, boat and walking tours; museums, Art Gallery of Nova Scotia and public library programs; indoor and outdoor events and activities like receptions, social events, conferences and training that are hosted by a business or organization; indoor and outdoor wedding ceremonies and funerals (including receptions and visitation) that are hosted by a business or organization; community meetings in rental spaces or where the public may be present; training hosted by a business or organization.

Restaurants and food courts; Nightclubs, casinos, bingo halls, VLT lounges; Entertainment and recreation centres (e.g., bowling, racing, arcades, billiards halls, etc.); Museums, art galleries; Movie theatres; Recreation facilities for physical, performance or recreational activity; Conferences, meeting spaces, halls, and rented space; Weddings and funerals held in public facilities; Professional sporting or performance events (spectator); Indoor adult sport and performance activities (participants); Private social events held in public facilities; Adult recreational activities (e.g., classes, groups); Amenities in hotels and condos, including fitness rooms, pools and game rooms. 
New

Brunswick

Saskatchewan ${ }^{2}$

Newfoundland

and Labrador

Prince

Edward

Island

Indoor festivals, performing arts and sporting events; Indoor and outdoor dining and drinking at restaurants, pubs and bars; Nightclubs, amusement centres, pool halls, bowling alleys and casinos; Movie theatres; Gyms, indoor group exercise, indoor pools and recreation facilities; Indoor organized gatherings like weddings, funerals, parties, conferences and workshops; Indoor organized group recreational classes and activities; Visiting a long-term care facility.

Restaurants, including in hotels or other lodgings (incl. outdoor patios); Nightclubs, bars, taverns buses and other establishments that serve alcohol; theatres; cinemas; bingo halls, casinos and other gaming establishments; concerts; live-music venues; fitness centres and gyms; stand-alone liquor and cannabis retail sales locations; and facilities hosting sporting events where tickets are required that have GST charged.

Gatherings of any size held for socializing, celebration, ceremony or entertainment hosted at a recognized business or organization, a rental room, community centre, or other venues used to host gatherings (e.g. weddings, funerals, birthday parties, baby showers, faith-based gatherings); Conferences, conventions and trade shows; Arenas; Indoor gyms and fitness facilities, yoga studios, and dance studios; Places where sports or recreational activities are practiced indoors; Places where group music, art, dance, and drama activities are practiced indoors, including bands, choirs, dance and music classes; Indoor entertainment facilities (arcades, trampoline parks, bowling alleys, billiard halls, golf, laser tag, indoor playgrounds, and paintball); Bars and lounges; Restaurants (indoor seated dining only, including food courts; does not apply to outdoor patios, take-out, delivery, or drive-thru services); Cinemas and performance spaces; Bingo halls; Personal service establishments including spas, esthetic services, hair salons, barber shops, body piercing, tattooing and tanning salons; Long-term care homes, personal care homes, assisted living facilities, community care homes (visitors only).

Indoor and outdoor organized gatherings/events, including sporting events and recreational activities, and spectators at youth sporting events or recreational activities; Concerts, and arts, theatre, and music events; Wedding and funeral receptions and wakes; Conferences, trade fairs and workshops; Group activities and classes like pottery, art and choir; Adult group and team sports for people 19 years of age and older; Food premises and licensed premises (indoor and patio dining), including: Restaurants, Cafes, Bars, Liquor tasting rooms in wineries, breweries or distilleries; Casinos and movie theatres; Indoor gyms, exercise/dance facilities/studios, swimming pools and skating rinks; Outdoor facilities for organized gatherings/events; Arcades and bowling alleys; Meetings where members of the general public may be present.

\section{Countries}

France $^{3} \quad$ Marquees, theaters, sporting or cultural performance venues, conference rooms; trade shows and exhibition fairs; outdoor establishments including zoological, amusement and theme parks; stadiums, sports establishments, swimming pools, sports halls; casinos, gaming halls and "bowling alleys"; outdoor sit/stand festivals; cinemas and theaters; monuments, museums and exhibition halls; libraries (excluding university and specialized libraries); sports competition; other events, cultural, sporting, fun or festive, organized in public space or in a place open to the public; worship establishments for events not of a religious nature; ships and boats, cruise ship type; discotheques, dance clubs and bars; fairgrounds, from a threshold of 30 stands or attractions; commercial catering activities (bars and restaurants, including on terraces); trade fairs and exhibitions, and professional seminars; health, social and medico-social services and establishments; longdistance travel by inter-regional public transport (domestic flights, TGV journeys, Intercity and night trains, inter-regional coaches); department stores and shopping centers of more than $20,000 \mathrm{~m}^{2}$.

Italy $^{3}$

Travel between different regions by air, train, ship, ferry or coach; Restaurants, bars, ice cream parlours and pastry shops for consumption at table indoors; Performances open to the public, sporting events, both outdoors and indoors; Museums and places of culture, shows; Swimming pools and gyms; Private parties, such as wedding receptions; Festivals and trade fairs; Conventions and congresses; Spas and fitness centres; Gaming halls and betting shops, bingo halls and casinos.

Germany $^{3}$

Visitor access to hospitals, nursing and care homes and assisted living facilities for the disabled; Access to indoor cafés and restaurants; Participation in indoor events and celebrations (e.g. information events, cultural events or sporting events); Using personal care services (e.g. hairdressers, beauticians, cosmetic services); Indoor sports (e.g. at gyms, swimming pools or sports centres); Accommodation (hotels, guesthouses): a test is to be taken for arrival and twice a week for the duration of the stay.

Notes: During the studied period: 1. Alberta's mandate allows a recent negative COVID-19 test in lieu of vaccination and allows businesses to opt out of the proof of vaccination requirement and instead be subject to stricter COVID-19 prevention protocols, e.g., capacity limits, distancing, etc. 2. Saskatchewan's mandate allows a recent negative COVID-19 test in lieu of vaccination. 3. France's, Italy's and Germany's mandates allow a recent negative COVID-19 test or a past positive test in lieu of vaccination. 